\title{
REFLEXIONES SOBRE EL ARTÍCULO 149.1.1 DE LA CONSTITUCIÓN: LA CLASIFICACIÓN DEL SUELO Y LA IMPOSIBLE IGUALDAD EN EL EJERCICIO DEL DERECHO A LA PROPIEDAD URBANÍSTICA*
}

\author{
Iñaki Agirreazkuenaga \\ Catedrático de Derecho Administrativo \\ Universidad del País Vasco \\ San Sebastián, España
}

Remisión Artículo: 12-2-2007

Remisión Definitivo: 12-2-2007

Palabras Claves: Art. 149.1.1 CE, Propiedad urbana, Derechos urbanísticos, Clasificación de suelo.

"Lavora come se non avessi bisogno dei soldi,

Ama come se nessuno ti abbia mai fatto soffrire,

Canta come se nessuno ti stesse sentendo,

Vivi come si il paradiso fosse sulla terra,

e, quando morirai, continuerai a vivere nella vita dei tuoi amici".

*Una breve dedicatoria al amigo que sigue viviendo entre sus amigos.

Cuantos hemos tenido la fortuna de conocer a Javier, sabemos que todavía vive entre los que lo tratamos, siguen vivos los buenos momentos, sigue viva su voz, su doctrina, su saber y por supuesto su humanidad. Su llama sigue viva con toda su fuerza en cada uno de sus escritos, incluso en sus emilios que conservamos en nuestros archivos, y que nos recuerdan toda su fuerza, e incluso si los reabrimos nos obligan a pulsar el never de la notificación, porque el now no creo que le llegase en estos momentos.

Cada vez que le citamos, cada vez que comentamos una anécdota, cada vez que evocamos un recuerdo, y evidentemente cada vez que le releemos, Javier vive y está entre nosotros. Con todo nuestro afecto -(tuyo y mío) como le gustaba a él escribir- le siento humilde, sabía escuchar, pedir consejo, y cuando lo recibía era sumamente agradecido. Por supuesto, era de una probidad e integridad absoluta, totalmente insobornable ${ }^{1}$, se mostraba y era de una sola pieza, no creo que tenía dobleces, y si por algo se caracterizaba era por ser muy directo, aunque en ocasiones le vencía la pasión, esa pasión que ponía en todo lo que hacía, sentía y le gustaba.

*El presente trabajo se enmarca en el Proyecto de investigación del Ministerio de Educación y Ciencia SEJ200404044/JURI.

\footnotetext{
${ }^{1}$ Muchos conocerán la anécdota del ex vicepresidente del Gobierno de España que acudió a su despacho a solicitar un trato de favor relacionado con unos terrenos de su familia estando redactando Javier el planeamiento general de un municipio, y todos imaginamos a Javier sorprendido, indignado y encolerizado echando de su despacho al personaje, tal como me lo relataba todavía con el paso de los años con cierto poso de amargura, quizá por una naturaleza humana tan extendida y tan ajena a su ser.
} 
A mí Javier siempre me pareció muy vital, alegre, crítico, jovial, trabajador incansable, muy estudioso, extremadamente curioso con todo y no solo con su trabajo, profundamente humano y apasionado, y en ocasiones doblemente apasionado en sus juicios, aunque siempre lúcido, abierto, inteligente, de tal modo que si se daba cuenta que podía haberse excedido, no tenía problema en excusarse, bien por propia iniciativa o a sugerencia de Consuelo.

Javier no era jurista, pero entendía perfectamente el Derecho urbanístico, si algo le caracterizaba era su afán por el estudio, por el conocimiento, por entender aquello que le resultaba ajeno por formación, pero que lo necesitaba para que las piezas le encajasen en el rompecabezas del Urbanismo.

Claramente tenía vocación universitaria, aunque por avatares del momento que le tocó vivir en la década de los sesenta, y por no haber encontrado el maestro que hubiese necesitado, se desvió de su inagotable sed de conocimiento y estudio, aunque todo ello lo compensó, tras un conocimiento práctico de su pasión urbanística, sabiendo abrirse y elegir una vía específica de estudio en la propia Administración, colaborando también con la Universidad.

Como ejemplo de su pasión por el estudio cabe recordar que su mejor plan era tener tiempo libre para estudiar, mejor en vacaciones, pero incluso con su media jornada de trabajo sacaba tiempo para ir al archivo correspondiente, o su fin de semana libre para encerrarse entre sus papeles. Como prueba reproduzco el email que me enviaba el 26 de mayo de 2005: "Mañana viernes voy por la mañana al Alcázar de Segovia a seguir hurgando en los archivos militares de los derribos de las murallas españolas entre 1854 y 1900... Es la porra lo que estoy sacando! Todo el nacimiento del urbanismo de los ensanches... Pero vuelvo por la tarde. Por lo cual, dependiendo de Consuelo, te puedes venir el sábado por la mañana a comer o cenar o dormir en mi casa..., como te venga mejor! Estaré trabajando en mi casa desde el viernes tarde al domingo: me llamas...y quedamos".

\section{I.-REFLEXIONES SOBRE EL ARTÍCULO 149.1.1 DE LA CONSTITUCIÓN}

Entre los títulos competenciales que permiten al Estado incidir en materia de urbanismo, destaca, sin duda, el referido a las "condiciones básicas" garantizadoras de una igualdad esencial de todos los titulares de derechos de propiedad del suelo sobre la base del artículo 149.1.1 $\mathrm{CE}$, que constituye, como es sabido, una notable peculiaridad en el panorama comparado de los sistemas de reparto territorial del poder en los Estados con grado de descentralización equiparable al de España.

Con una argumentación que no puede considerarse como demasiado clara, el TC ha afirmado que el artículo 149.1.1 ${ }^{\circ}$ CE habilita al legislador estatal para regular las "condiciones básicas" que garanticen la igualdad en el ejercicio de los derechos y deberes constitucionales en sí mismos considerados. Dada la fuerza expansiva de los derechos y la función inspiradora de todo el ordenamiento jurídico que tienen atribuida (artículo 10.1 CE), el ámbito y sentido del artículo 149.1.1 $\mathrm{CE}$ quedaría desbordado si operase como una especie de título horizontal, capaz de introducirse en cualquier materia o sector del ordenamiento, por el mero hecho de que pudieran ser reconducidos, siquiera sea remotamente, hacia un derecho o deber constitucional (STC 61/1997, FJ 7b). 
No obstante, ¿cuál es la proyección que este título competencial tiene en la materia de urbanismo? La competencia estatal ex artículo 149.1.1 $\mathrm{CE}$, ¿permite incidir en cualquier ámbito competencial, incluso en aquellos ámbitos materiales en que el Estado carece de competencias? ¿Cuál es la extensión de las condiciones básicas que el Estado considera que debe regular para garantizar la igualdad de todos los ciudadanos en el ejercicio del derecho de propiedad? ¿Cómo se ha llegado a configurar el "derecho a la propiedad urbana" para justificar la incidencia competencial del Estado en ámbitos puramente urbanísticos, si el Estado no puede regular ni de forma supletoria esta materia?

¿Existe verdaderamente un derecho a la propiedad urbana derivado de la propiedad del suelo o, por el contrario, resulta preciso distinguir entre la mera propiedad del suelo que no otorga ningún derecho urbanístico y los propios derechos urbanísticos derivados del planeamiento y que son, por tanto, otorgados por los poderes públicos? Es evidente que el suelo es una condición indispensable de la materialización del derecho a la urbanización y a la edificación, pero no, así, la determinación de la propiedad del suelo. En consecuencia, ¿se puede afirmar que es la propiedad la que otorga derechos urbanísticos? Y si el ser propietario de un terreno en España no otorga, in genere, ningún derecho urbanístico, ¿podría el Estado incidir en la regulación de la propiedad urbana (o mejor, urbanística) bajo el argumento de que a él le corresponde la regulación de las condiciones básicas que garanticen la igualdad de todos los españoles en el ejercicio de los derechos?

Como se sabe, el Tribunal Constitucional ha considerado que el Estado es competente para garantizar desde la perspectiva de la intervención pública, las condiciones de igualdad (artículo 149.1.1 ${ }^{\circ} \mathrm{CE}$ ) y sólo sus condiciones básicas, óptica distinta, sin duda, de la que proporciona la competencia exclusiva del Estado sobre la legislación civil a que se refiere el $\mathrm{n}^{\circ} 8$ del artículo 149.1. Ello significa que la legislación estatal dictada al amparo del artículo 149.1.1 ${ }^{\circ} \mathrm{CE}$ en relación con aquellas manifestaciones del dominio sobre las que las Comunidades Autónomas sí ostentan competencias no puede utilizarse para regular la política autonómica sectorial correspondiente, puesto que tal resultado supondría vaciar de todo contenido la competencia autonómica. Más en concreto, "el indicado título competencial sólo tiene por objeto garantizar la igualdad en las condiciones de ejercicio del derecho de propiedad urbana y en el cumplimento de los deberes inherentes a la función social, pero no, en cambio, la ordenación de la ciudad, el urbanismo entendido en sentido objetivo. A través de esas condiciones básicas, por tanto, no se puede configurar el modelo de urbanismo que la Comunidad Autónoma y la Administración local, en el ejercicio de sus respectivas competencias, pretendan diseñar, ni definir o predeterminar las técnicas o instrumentos urbanísticos al servicio de esas estrategias territoriales, aunque, como se verá, puedan condicionar indirectamente ambos extremos" (STC 61/1997, FJ 9.b).

En vista de todo ello, se pretende analizar la doctrina y jurisprudencia recaída en torno al artículo 149.1.1 $\mathrm{CE}$, precepto que requiere una primera atención al margen del régimen urbanístico (1); para continuar, en segundo lugar, con la interpretación del artículo 149.1.1ํ. $\mathrm{CE}$ a la luz de la STC 61/1997 (2). En tercer lugar, se analiza el artículo 149.1.1 CE como eventual fuente de competencias urbanísticas para el Estado, con un primer apartado de reflexión sobre el derecho de propiedad y el artículo 149.1.10 CE a la luz de la STC 37/1987 (3.A), para adentrarnos a continuación en las modulaciones de esta doctrina por la STC 61/1997 (3.B), y la posterior STC 164/2001 que, como se sabe, confirma la constitucionalidad de la Ley 6/1998, de 13 de abril, de Régimen del Suelo y Valoraciones en la generalidad de 
sus apartados aprobados en desarrollo del artículo 149.1.1 CE (3.C). Por último, se finaliza este capítulo con unas reflexiones críticas en relación con la doctrina jurisprudencial asentada en estos momentos en el ordenamiento jurídico español, y de la que un ejemplo, en su forma más cruda, lo representa la interpretación del artículo $149.11^{\circ} \mathrm{CE}$ en el voto particular a la STC 188/2001 suscrito, entre otros, por el a la sazón Presidente del Tribunal Constitucional junto con el ponente de la STC 164/2001 (4).

\section{1.-La interpretación doctrinal y jurisprudencial del artículo $149.1 .1^{\circ} \mathrm{CE}$ al margen del régimen urbanístico.}

La función del artículo 149.1.1 ${ }^{\circ}$ CE que reconoce al Estado la competencia exclusiva para "la regulación de las condiciones básicas que garanticen la igualdad de todos los españoles en el ejercicio de los derechos y en el cumplimiento de los deberes constitucionales", ha sido muy discutida, existiendo interpretaciones muy divergentes, aunque en todas ellas se converge en su complejidad y en la necesaria prudencia al interpretar y, sobre todo, aplicar este precepto constitucional.

Uno de los primeros estudios dedicados a dicho título competencial fue el realizado por J. L. CARRO FERNÁNDEZ-VALMAYOR ${ }^{2}$, quien consideró que la garantía de la igualdad encomendada al Estado por el artículo 149.1.1 ${ }^{\circ} \mathrm{CE}$ se refiere al ejercicio de todos los derechos y al cumplimiento de todos los deberes constitucionales sin distinción, extendiéndose a la totalidad de los consagrados en el capítulo II del Título primero de la Constitución. Destacó, entre otras cuestiones, la doble virtualidad que posee dicha norma, al aparecer, por un lado, como una cláusula general de intervención normativa puntual en los supuestos de violación del mínimum constitucional de igualdad por parte de la legislación de una o varias Comunidades Autónomas; y por tratarse, de otro lado, de una competencia sustantiva ejercitable espontáneamente y con independencia del supuesto de violación constitucional.

En cuanto a la expresión "condiciones básicas" utilizada por la norma del artículo 149.1.1 CE, J. L. CARRO FERNÁNDEZ-VALMAYOR señaló que no significa en absoluto que estemos ante una competencia compartida, sino que la competencia que otorga dicha norma se refiere única y exclusivamente al ejercicio y cumplimiento igualitario de derechos constitucionales insusceptible de desarrollo autonómico posterior. Dichas condiciones básicas encuentran su manifestación a través de la emanación de una ley específica garantizadora del citado mínimum constitucional de igualdad que debe revestir la forma de ley orgánica en la medida en que tiene como contenido necesario la regulación del principio de igualdad en cuanto tal. Finalmente, distinguió las leyes que son manifestación de la competencia del 149.1.1 ${ }^{\circ} \mathrm{CE}$ de las leyes de armonización del 150.3 CE, por cuanto estas últimas tienen una finalidad distinta y un ámbito material más extenso, así como un procedimiento de aprobación diferente.

Con posterioridad al analizar I. de OTTO el artículo 149.1.1 $\mathrm{CE}$ destacaba las necesarias cautelas en su interpretación, de tal forma que el Estado no podía ampliar, en virtud de este precepto, las competencias enumeradas en el artículo $149.1 \mathrm{CE}$, en sus diversos apartados ${ }^{3}$.

\footnotetext{
2 "Contenido y alcance de la competencia del Estado definida en el artículo 149.1.1 de la Constitución", REDC, n 1 , 1981, pp. 155-156.

3 “Los Derechos Fundamentales y la potestad normativa de las Comunidades Autónomas", RVAP, nº 10, 1984.
} 
No obstante, dicha cláusula sí sería válida para sustraer de la competencia autonómica aquellos aspectos en los cuales "estén en juego condiciones básicas para el ejercicio de un derecho", exigiendo las condiciones básicas que la diferencia sea "sustancial". Este autor consideró que la interpretación del precepto debe ser estricta en lo que hace a la extensión de la regulación a las instituciones conexas, ya que "los derechos y deberes tan ampliamente comprendidos en el artículo 149.1.1 $\mathrm{CE}$ podrían conducir a extender sin límites y por conexiones amplias las competencias exclusivas del Estado".

Con posterioridad, otros planteamientos doctrinales han negado al artículo 149.1.1 $\mathrm{CE}$ la función de título competencial del Estado, para reconocerle un mero valor declarativo de los fines que deben alcanzar las restantes competencias estatales ${ }^{4}$, sirviendo de límite a las competencias autonómicas ${ }^{5}$.

Quien durante años fuera Vicepresidente del Tribunal Constitucional, L. LÓPEZ GUERRA, después de señalar la diferencia entre los artículos $138.2,139.1$ y $149.1 .1^{\circ} \mathrm{CE}$, indicaba sobre este último que su aplicación será innecesaria o escasa en lo que se refiere a los artículos 14 a $29 \mathrm{CE}$, así como a los artículos 30 a $38 \mathrm{CE}$. En cuanto a los primeros, porque la igualdad se logra gracias a la reserva de ley orgánica, y en los segundos, porque tienen a su vez garantizado un contenido esencial (artículo 53.1 CE). El artículo 149.1.1 ${ }^{\circ} \mathrm{CE}$ se debía utilizar, en su opinión, para interpretar otros preceptos constitucionales, encontrando una aplicación autónoma en la actividad de fomento estatal para asegurar condiciones de disfrute igualitario de derechos económicos y sociales ${ }^{6}$.

Existía por tanto, un común juicio doctrinal y jurisprudencial sobre el artículo 149.1.1ํㅡ $\mathrm{CE}$ que mantenía que la generalidad de los términos de dicho precepto constitucional implicaba un peligro indudable para las competencias de las Comunidades Autónomas, por lo que se imponía negar su carácter de competencia estatal, bien considerándolo únicamente como criterio de interpretación del resto de competencias del Estado, o aceptándolo como límite negativo de las competencias autonómicas que impide la introducción de divergencias irrazonables y desproporcionadas en las condiciones básicas de igualdad de los españoles, o, en último extremo, admitiéndolo como título complementario o modulador de los demás. Lo que se corroboraba, asimismo, por el Tribunal Constitucional que evitaba aplicarlo como título autónomo y lo utilizaba para modular, reforzar o complementar otras competencias.

Eliseo AJA, no obstante, criticó tal enfoque, por dos razones diferentes. En primer lugar, porque la ubicación sistemática de dicho precepto en el frontispicio de las competencias del Estado impedía reducirlo a criterio de interpretación o límite negativo para las Comunidades Autónomas, no mostrando ninguna duda de que la Constitución lo considera como título competencial. En segundo lugar, por las propias consecuencias que venía produciendo su aparente devaluación como criterio o principio, dado que esta apariencia inofensiva estaba

\footnotetext{
${ }^{4}$ BAÑO LEÓN, J. M., Las Autoridades Territoriales y el principio de uniformidad de las condiciones de vida, INAP, Madrid, 1988, p. 266.

${ }^{5}$ BAÑO LEÓN, J. M., Las Autoridades Territoriales y el principio de uniformidad de las condiciones de vida, Op. cit., p. 266; LASAGABASTER, I., El sistema competencial en el Estatuto de Autonomía, IVAP, Oñati, 1989, p. 114.

${ }^{6}$ LÓPEZ GUERRA, L., "Consideraciones sobre la regulación de las condiciones básicas del artículo $149.1 .1^{\circ}$ CE”, en PÉREZ CALVO, A. (coord.), Normativa básica en el ordenamiento español, Madrid, 1990, p. 93.
} 
impulsando un creciente recurso a él y, además, provocaba la distorsión de otros principios y títulos competenciales, porque la consideración "solo" como criterio de interpretación o modulación de otras competencias, estaba dando pie a un incremento muy notable de su utilización por el legislador, actuando en general como ampliación injustificada de las competencias estatales ${ }^{7}$.

E. AJA consideraba el artículo $149.1 .1^{\circ} \mathrm{CE}$ como una regla competencial clara, tanto desde el punto de vista literal como sistemático. En su opinión no se trataba de una competencia exclusiva, como el Tribunal Constitucional se había encargado de matizar, sino sólo una competencia para la regulación, por lo que implicaría normalmente la colaboración de las Comunidades Autónomas en su realización, sin que pudiera concluirse una exacta uniformidad aunque sí la consecución del objetivo establecido por el Estado.

En opinión de E. AJA, la competencia del artículo 149.1.1 $\mathrm{CE}$ no viene definida por la referencia a una materia sino a un objetivo que consiste en la consecución de la igualdad en las condiciones básicas del ejercicio de los derechos y deberes de todos los ciudadanos. Igual que sucede en el campo de los derechos con el artículo $14 \mathrm{CE}$, que puede referirse a cualquier relación jurídica y carece de un sector material propio, el objeto del artículo 149.1.1ํㅡ CE no es una materia concreta sino que puede afectar a las relaciones que se entablen sobre los derechos y deberes de los ciudadanos. Asimismo señalaba que el término de condiciones básicas es muy diferente al de bases y normas básicas de otros números del artículo 149.1 CE, porque éstas delimitan la función normativa del Estado y, en cambio, las condiciones básicas no determinan la posible intervención normativa estatal, sino las circunstancias tanto materiales como jurídicas que pueden determinar la igualdad.

En consecuencia, E. AJA concluía que, en la práctica, el principal sentido de este precepto es otorgar al Estado un título competencial para la realización del principio social (artículo 9.2 CE), justamente porque estos principios en sí mismos no son títulos competenciales, como afirmó con rotundidad la STC 146/1986, de 20 de julio (FJ 2). Es por ello que el contenido de las condiciones básicas difícilmente puede ser determinado a priori, porque justamente dependerá de la irrupción de algún nuevo factor económico o social, o de la decisión política de generalizar un nuevo estándar social.

En este sentido AJA consideraba que la principal condición para que el Estado pueda utilizar este título de intervención consiste en que carezca de otro título sobre la misma materia que le permita garantizar la igualdad de los derechos y deberes, porque de lo contrario perdería su sentido. Desempeña, por tanto, una función de cláusula de cierre. Consecuentemente el Estado no puede acudir al $149.1 .1^{\circ} \mathrm{CE}$ cuando posea competencias para garantizar la igualdad que requiere el precepto, sean exclusivas, concurrentes o compartidas, si bien frecuentemente ha sido utilizado dicho título competencial con la finalidad de reforzar la competencia estatal y de extenderla más allá de sus límites, como en la STC 42/1981, sobre las bibliotecas de Cataluña, o la STC 122/1989, sobre las guías de turismo de Cantabria. Con todo, insiste en el

\footnotetext{
${ }^{7}$ AJA, E., "El artículo $149.1 .1^{\circ}$ de la Constitución como cláusula de cierre del principio de igualdad social", La función del artículo 149.1.1 ${ }^{\circ} \mathrm{CE}$ en el sistema de distribución de competencias. Seminario celebrado en Barcelona el 7 de junio de 1991, Institut d’Estudis Autonòmics, Barcelona, 1992, p. 28 y ss.
} 
carácter excepcional y residual del referido título competencial, invitando al Tribunal Constitucional a buscar un método específico de interpretación.

En cuanto a la interpretación constitucional del artículo 149.1.1 $\mathrm{CE}$, con carácter previo a la STC 61/1997, son muy escasas las Sentencias en las que dicho precepto aparece como único título habilitador de la acción estatal. Desde esta perspectiva, la "garantía de la igualdad" atribuida al Estado serviría, no tanto como fuente propia de competencias, sino para precisar el alcance de una competencia estatal derivada de otros títulos (destacan en este sentido la STC 5/1981, dictada con ocasión de la impugnación contra el Estatuto de Centros Docentes; la STC $32 / 1983$, en materia de registro sanitario; y la STC 64/1989, en un conflicto promovido por la Comunidad Autónoma de Galicia frente a actuaciones estatales en materia de ayudas a empresas periodísticas). Aunque tampoco faltan ejemplos en la jurisprudencia constitucional de afirmaciones expresas del TC en el sentido de que del artículo 149.1.1 ${ }^{\circ} \mathrm{CE}$ pueden derivarse directamente competencias estatales. Otra cosa es que una vez que el TC haya formulado esa afirmación de principio, la haya traducido en fallos concretos: en algunos supuestos, la confirmación abstracta de la existencia de habilitaciones competenciales derivadas del artículo 149.1.1 ${ }^{\circ} \mathrm{CE}$ no se ha visto seguida del reconocimiento concreto de esa habilitación en el caso en cuestión, como sucede en la STC 82/1986, en el recurso frente a la Ley vasca de normalización del euskera; o en la STC 52/1988, dictada con ocasión de una impugnación estatal de normas de la Generalidad de Cataluña referentes a la producción y homologación de máquinas para juegos de azar.

Donde sí se reconocen las consecuencias de la competencia estatal ex artículo 149.1.1 ${ }^{\circ} \mathrm{CE}$, es en la decisión recaída en la STC 149/1991, con ocasión de los recursos planteados frente a la Ley de Costas por diversas Comunidades Autónomas. EI TC se plantea si la legislación estatal protectora del medio ambiente puede incidir, no ya en el dominio marítimo-terrestre (de titularidad estatal), sino también en los terrenos colindantes, en que tal titularidad no existe, y sobre los que las Comunidades Autónomas han podido asumir competencias de ordenación del territorio. La respuesta del TC es afirmativa, fundándose en la garantía de la igualdad en ejercicio de los derechos al medio ambiente reconocidos en el artículo $45 \mathrm{CE}$. El artículo 149.1.1 ${ }^{\circ} \mathrm{CE}$, señala el TC, opera en el supuesto en cuestión, asegurando una igualdad básica en el ejercicio a disfrutar de un medio ambiente adecuado al desarrollo de la persona y en relación con el dominio público marítimo-terrestre, tanto en lo que se refiere a su mantenimiento como, entre otros aspectos, garantizando su accesibilidad, para lo que es imprescindible imponer servidumbres sobre los terrenos colindantes y limitar las facultades dominicales de sus propietarios. No obstante, como indica L. LÓPEZ GUERRA, la resuelta aplicación en estos supuestos del artículo 149.1.1 $\mathrm{CE}$ se ve inmediatamente matizada por la concurrencia de la competencia estatal para la protección del medio ambiente, consagrada como reserva estatal en lo que se refiere a la legislación básica, por el artículo 149.1.23 CE. La naturaleza sui generis de la cláusula de garantía de la igualdad se traduce, pues, incluso en aquellos casos en que parece más consciente su aplicación, como título estatal habilitante ${ }^{8}$.

\footnotetext{
${ }^{8}$ L. LÓPEZ GUERRA, "La doctrina del TC en relación con el artículo 149.1.1 CE", La función del artículo 149.1.1 CE en el sistema de distribución de competencias. Seminario celebrado en Barcelona el 7 de junio de 1991, Op.cit. pp. 2223.
} 


\section{2.- La interpretación del artículo $149.1 .1^{\circ} \mathrm{CE}$ a la luz de la STC 61/1997, de 20 de marzo9}

Antes de examinar la incidencia del artículo 149.1.1 $\mathrm{CE}$ en materia de urbanismo, resulta preciso poner de relieve la delimitación positiva y negativa que realiza el TC de la competencia estatal ex artículo 149.1.1 $\mathrm{CE}$. Y de su doctrina se pueden extraer las siguientes conclusiones:

-El contenido del artículo 149.1.1 ${ }^{\circ} \mathrm{CE}$ no es identificable con el de otros preceptos de la norma constitucional, tales como los artículos 138.2 y $139.1 \mathrm{CE}$, en cuanto que definen presupuestos o límites pero no títulos competenciales, o el artículo 139.2 CE que es más bien expresión de la unidad del mercado y de la libre circulación.

-El precepto 149.1.1 ${ }^{\circ} \mathrm{CE}$ no es tampoco trasunto -en el plano competencial- del artículo $14 \mathrm{CE}$ por no establecer éste una prohibición al legislador autonómico de trato diferenciado (lo que sería contradictorio con el Estado autonómico mismo), sino que únicamente excluye el trato divergente que sea desproporcionado e irrazonable.

-El concepto de "condiciones básicas" utilizado por el artículo 149.1.1 CE no es sinónimo de legislación básica, y en tal sentido se afirma que el precepto no atribuye a las instituciones generales del Estado la fijación de las normas básicas que garanticen la igualdad en el ejercicio de los derechos y las libertades y el cumplimiento de los deberes constitucionales, sino tan sólo la de aquéllas condiciones básicas que tiendan a garantizar la igualdad.

Consecuentemente, la regulación estatal no puede ser una normación acabada y completa del correspondiente derecho o deber constitucional, por lo que las Comunidades Autónomas pueden establecer normas definitorias del régimen jurídico del correspondiente derecho o deber en el ámbito de sus competencias. La competencia ex artículo 149.1.1 ${ }^{\circ} \mathrm{CE}$ no se mueve de ninguna manera en la lógica propia de las bases-desarrollo, sino que es exclusiva, aunque sólo desde determinada perspectiva (la de las condiciones básicas que tiendan a garantizar la igualdad), de tal suerte que la legislación estatal puede no ser susceptible de desarrollo. La legislación reguladora de las condiciones básicas desempeña, en definitiva, una función de definición del marco en el que debe inscribirse la legislación autonómica. Por eso deben expresarse preferentemente unos principios o reglas generales, y no consistir en regulaciones detalladas, pues para su legitimación no basta con que dejen un cierto espacio al legislador autonómico.

Las condiciones básicas del artículo 149.1.1 ${ }^{\circ} \mathrm{CE}$ no son identificables con el contenido esencial de los derechos constitucionales. Este contenido esencial representa una técnica de garantía frente al poder público (concretamente frente al legislador) para la propia regulación material de los derechos constitucionales al margen de la determinación de competencias.

En cuanto a su ámbito material o alcance horizontal, la materia sobre la que se proyecta el artículo 149.1.1 ${ }^{\circ} \mathrm{CE}$ aparece integrada por los derechos constitucionales en sentido estricto y

\footnotetext{
${ }^{9} \mathrm{Al}$ efecto resultan de obligada lectura los trabajos de J. BARNES, "Distribución de competencias en materia de urbanismo. Estado, Comunidades Autónomas, Entes Locales", Barcelona, 2002; "Legislación básica y artículo 149.1.1ª CE", publicado en "Informe Comunidades Autónomas 2003", Barcelona 2004, pp. 816-828; y "Problemas y perspectivas del artículo 149.1.1 ${ }^{\text {a }}$ CE", Institut d’Estudis Autonòmics, Barcelona, 2004.
} 
los deberes básicos correspondientes. Pero las condiciones básicas se predican de los derechos y deberes constitucionales en sí mismos, no de los sectores materiales en los que éstos se instalan u operan. De ahí que el artículo 149.1.1 ${ }^{\circ} \mathrm{CE}$ sólo puede otorgar, en su caso, cobertura a las condiciones que tienen estrecha relación (directa e inmediata) con los referidos derechos y deberes. En ningún supuesto puede el precepto operar como título horizontal capaz de justificar - por el mero hecho de la posibilidad de reconducción a un derecho o deber constitucionales- la penetración estatal en cualquier materia o sector del ordenamiento jurídico.

Por su parte, el TC considera el artículo 149.1.1 ${ }^{\circ} \mathrm{CE}$ como un título competencial autónomo (no residual) y constreñido al ámbito normativo, que permite a las instituciones generales del Estado la regulación, si bien limitada, de las condiciones básicas (no por tanto, el diseño acabado del régimen jurídico de los derechos y deberes constitucionales). El elemento teleológico del título competencial consiste en la igualdad de todos los españoles pero dicho precepto no expresa prohibición alguna de heterogeneidad normativa autonómica.

En lo que se refiere al contenido o significado de las condiciones básicas, el TC ha declarado que el artículo $149.1 .1^{\circ} \mathrm{CE}$ autoriza el dictado de normas que afecten al contenido primario del derecho o a las posiciones jurídicas fundamentales en la medida en que sean estrictamente imprescindibles o necesarias para garantizar esa igualdad primaria. Por tanto, las condiciones básicas no abarcan ni comprenden en ningún caso la regulación acabada del derecho constitucional de que se trate, ni su régimen completo, sino sólo la estructura fundamental, es decir, las facultades elementales, los límites esenciales, los deberes fundamentales y las prestaciones básicas.

En todo caso, se trata siempre de las condiciones imprescindibles o necesarias para garantizar la igualdad, que no puede consistir en una igualdad formal absoluta. No se está, pues, ante cualquier condición material, porque ello daría lugar al solapamiento con otras competencias estatales, o a la simple marginación o erosión de las competencias autonómicas.

Asimismo, las condiciones básicas pueden comprender ciertas premisas o presupuestos previos, externos al derecho mismo, siempre y cuando guarden una relación necesaria e inmediata con esas condiciones básicas, tales como el objeto o ámbito material sobre el que recaen las facultades que integran el derecho, los deberes, los requisitos mínimos o condiciones básicas en que ha de ejecutarse el derecho, los requisitos indispensables o el marco organizativo que posibilitan el ejercicio mismo del derecho.

Por lo tanto, las condiciones básicas pueden regular algo de contenido interno y algo de sus presupuestos o premisas previas o externas. Pero en cualquiera de las modalidades debe tratarse de una regulación limitada que no equivale a bases, legislación básica o norma básica, ni en su extensión ni en lo que ésta tiene de regulación sistemática y coherente, completa de una porción de la materia. Habrá que estar a lo que demande la igualdad de todos los españoles, elemento teleológico o finalista del título competencial, y en la medida en que ello sea imprescindible o necesario para salvaguardar esa igualdad.

Pero las condiciones básicas no pueden ser interpretadas por el legislador estatal de tal modo que, en la práctica, determinen el vaciamiento de cualquier competencia autonómica sectorial en relación con materias en las que se encuentre algún derecho constitucional. De esta forma, 
si se anuda lo desarrollado hasta este punto con el siguiente, aunque las normas reguladoras, por ejemplo, de las condiciones básicas de la propiedad urbanística establezcan los criterios o trazos elementales del dominio, no pueden ser de tal extensión e intensidad que predeterminen todo un modelo de urbanismo, porque es a las Comunidades Autónomas a las que les incumbe disciplinar el régimen jurídico del urbanismo. En efecto, la misma existencia del artículo 149.1.1 ${ }^{\circ} \mathrm{CE}$ se explica sobre la base de que a las Comunidades Autónomas les incumbe la ordenación de importantes sectores materiales, y en consecuencia, incidir en el ejercicio de incontables derechos constitucionales, como por ejemplo, la propiedad y la libertad de empresa. En otro caso, si se quisiera que el Estado fije las bases del régimen jurídico urbanístico, no habría más remedio que añadir un nuevo ordinal al artículo 149.1 de la Constitución.

\section{3.- El artículo $149.1 .1^{\circ} \mathrm{CE}$ como fuente de competencias urbanísticas para el Estado.}

\section{A) Una primera reflexión sobre el derecho de propiedad y el artículo 149.1.1 CE.}

Con ocasión de enjuiciar la constitucionalidad de la Ley 8/1984, de 3 de julio, de Reforma Agraria de Andalucía, el TC dictó la Sentencia 37/1987, de 20 de marzo, que contiene una interesante doctrina sobre el contenido esencial de la propiedad, la función social, la expropiación forzosa y el alcance de las regulaciones sobre estas materias por parte de las Comunidades Autónomas. Si bien esta Sentencia se refiere a la propiedad agraria, en todo su contenido hay claras referencias a la propiedad urbana y a los instrumentos de planificación, al propio tiempo que aborda múltiples cuestiones relacionadas con el contenido esencial de la propiedad y al principio de igualdad territorial.

Al efecto, caben ser destacadas las siguientes reflexiones en torno al artículo $149.1 .1^{\circ} \mathrm{CE}$ y el derecho de propiedad, en Sentencia en la que fue ponente Jesús LEGUINA:

-Como primera afirmación se destaca que el artículo 149.1.1 $\mathrm{CE}$ no habilita al Estado para realizar una regulación unitaria y uniforme del derecho de propiedad en todo el territorio español, ni ello se compadece con las competencias atribuidas a las Comunidades Autónomas por sus Estatutos de Autonomía y por las Leyes, conforme a la Constitución.

-"La función social de la propiedad, determinada de acuerdo con las leyes, presupone la identificación de los fines de interés general que, sin perjuicio de la utilidad de su titular, están llamados a satisfacer los bienes objeto de dominio privado. Por lo que concierne singularmente a la propiedad inmobiliaria, es evidente que esos fines de interés general pueden justificar el empleo de distintos instrumentos jurídicos en atención a la propia localización de los bienes o en razón de las cambiantes condiciones económicas sociales, e incluso, de orden cultural en cada parte del territorio".

-"La definición de la función social de la propiedad no es algo que deriva sustancialmente de una regulación unitaria del derecho de propiedad ni es tampoco aceptable que, al socaire de una ordenación uniforme de la propiedad privada, puedan anularse las competencias legislativas que las CCAA tienen sobre todas aquellas materias en las que entran en juego la propiedad y otros derechos de contenido patrimonial..." 
-La función social del derecho a la propiedad y más aún, su contenido, no puede ser igual en relación con cada tipo de bienes. Por ello no tiene sentido reservar al Estado la determinación abstracta y uniforme de la función social del derecho a la propiedad. Las condiciones básicas que al Estado compete regular ex artículo 149.1.1 CE habrán de ser diversas según la forma de propiedad de que se trate, porque el alcance o la amplitud de las competencias legislativas estatales o autonómicas sobre el derecho puede variar según el tipo de propiedad de que se trate (intelectual, urbana, agraria, cultural, forestal...) o la perspectiva que se adopte (Derecho público o Derecho privado).

Así, "la propiedad urbana presenta una connotación singular y característica que la diferencia de otras expresiones del dominio, como por ejemplo la propiedad agraria, y que reside en la naturaleza artificial y enteramente convencional de su contenido (volumen edificatorio) que lo distingue del uso natural del suelo o conforme con la naturaleza (el agrario, forestal o pecuario, o mejor, el rústico en sentido amplio), lo que puede demandar una intervención pública más incisiva y sistemática para delimitar el estatuto dominical de cada porción del suelo urbano, si el poder público no desea circunscribir su acción al establecimiento de limitaciones externas, puntuales, esporádicas y asistemáticas. Todo el complejo proceso urbanístico, su diseño y disciplina, por su peculiar naturaleza (obra del hombre) y carácter sistemático e integral, puede exigir una regulación más densa que la normación de otras formas de propiedad del suelo, como la agraria".

-La dimensión institucional del derecho de propiedad privada no puede desligarse de la regulación de los concretos intereses generales que imponen una delimitación específica de su contenido. "En consecuencia, corresponde a quien tiene atribuida la tutela de tales intereses -0 lo que es lo mismo, la competencia en relación con cada materia que pueda incidir sobre el contenido de la propiedad- establecer, en el marco de la Constitución, las limitaciones y deberes inherentes a la función social de cada tipo de propiedad".

-Por último se apunta que "... aunque pudiera entenderse que el artículo 149.1.1ํ CE permite al Estado atraer a su ámbito de competencia una potestad normativa en relación con la función social de la propiedad sobre cualquier tipo de bienes y en virtud de cualesquiera intereses de carácter público..., de ello no cabría concluir sino que el Estado podría regular las condiciones básicas que garanticen una igualdad de trato -asimismo básica o esencial- de todos los españoles en el ejercicio ( $y$ en el contenido) de sus derechos de propiedad. Pero ello, sin perjuicio de que las CCAA puedan dotarse, en el ámbito de sus respectivas competencias, de una legislación propia que respete la regulación básica estatal que pudiera en el futuro formularse o, en su caso, los principios de dicha regulación que puedan inducirse de las leyes estatales vigentes, de acuerdo con la Constitución".

B) Las modulaciones de esta doctrina en la STC 61/1997.

La STC 61/1997, de 20 de marzo, sobre el TRLS de 1992, concluye que, por lo que al derecho de propiedad y su función social concierne, al Estado incumbe establecer algunas piezas de las facultades básicas o fundamentales y de los deberes más elementales de cada expresión de la 
propiedad, y a las Comunidades Autónomas completar ese régimen, al legislar en el ámbito de la respectiva política sectorial de su competencia.

Con carácter general, al Estado le compete regular las condiciones básicas que garanticen la igualdad de todos los propietarios del suelo en el ejercicio de su derecho de "propiedad urbana", es decir, la igualdad básica en lo que se refiere a las valoraciones y al régimen urbanístico de la propiedad del suelo.

El título del artículo 149.1.1 $\mathrm{CE}$ no habilita para establecer una regulación uniforme de la propiedad privada y su función social, ni esa pretendida uniformidad puede servir de pretexto para anular las competencias legislativas que las Comunidades Autónomas tienen sobre todas aquellas materias en las que entre en juego la propiedad.

Al Estado le corresponde establecer la regulación del contenido básico y primario del derecho de propiedad, en la medida en que afecte a las condiciones básicas de su ejercicio, pero el referido título competencial no habilita por sí mismo para que el Estado pueda regular cualquier circunstancia que, de forma más o menos directa, pueda incidir sobre la igualdad en el ejercicio del derecho. La igualdad que se persigue no es la identidad de las situaciones jurídicas de todos los ciudadanos en cualquier zona del territorio estatal, lo que sería incompatible con la opción de un Estado organizado en la forma establecida en el Título VIII CE; sino que la igualdad perseguida es la que queda garantizada con el establecimiento de las condiciones básicas, que establecen un mínimo común denominador y cuya regulación sí puede ser competencia del Estado.

Por lo tanto, mediante la regulación de las condiciones básicas no se puede configurar el modelo de urbanismo que la Comunidad Autónoma y la Administración local pretendan diseñar, definir o predeterminar aunque lógicamente pueda verse condicionado.

De acuerdo con lo declarado por el TC, podrían hallar cobijo en el artículo 149.1.1 ${ }^{\circ} \mathrm{CE}$, de un lado, las facultades dominicales relativas a la adquisición del contenido urbanístico (aprovechamiento o edificabilidad) susceptible de apropiación privada, su valoración y los presupuestos previos para que pueda nacer el derecho de "propiedad urbana".

En tal sentido, el artículo 149.1.10 CE permitiría a las instituciones generales del Estado opciones diversas y, en cuanto a las condiciones básicas, modelos diferentes de "propiedad urbana o urbanística", cuya influencia sobre el entero estatuto legal de esta forma de propiedad no cabría desconocer. Por todo ello, de modo conclusivo, de la STC 61/1997 sería necesario retener que:

-Las instituciones generales del Estado pueden plasmar una determinada concepción del derecho de propiedad, en sus líneas entendidas como más fundamentales.

-Las Comunidades Autónomas pueden dictar normas atinentes al derecho de "propiedad urbana" con respeto a las condiciones básicas aprobadas por la legislación estatal.

-El artículo 149.1.1 $1^{\circ} \mathrm{CE}$ puede encontrar su mejor expresión en criterios, principios o reglas generales, directivas u obligaciones de resultado, que en definitiva sirvan para garantizar la 
igualdad en las posiciones jurídicas fundamentales, sin menoscabo de las competencias urbanísticas de las Comunidades Autónomas y, en consecuencia, de la indudable competencia de éstas para dictar también normas sobre la denominada propiedad urbana o urbanística.

\section{C) La evolución jurisprudencial culminada con la STC 164/2001.}

Tras la aprobación de la Ley 6/1998, de 13 de abril, de Régimen del Suelo y Valoraciones, la STC 164/2001, de 11 de julio, recaída en torno a su contenido dibuja un panorama jurisprudencial evolutivo en el que se agudizan las tesis de la doctrina contenida en la STC 61/1997. Entre estas tesis, por lo que concierne a este trabajo, la primera idea fundamental es que se reafirma el valor autónomo del título competencial con base exclusiva en el artículo 149.1.1 ${ }^{\circ} \mathrm{CE}$. Al respecto, si bien prima facie se determina que al Estado corresponde la regulación de las condiciones básicas que garanticen la igualdad de todos los españoles en el ejercicio del derecho a la propiedad urbana, lo que de facto sucede es que a la vista de la Disposición Final Única de la LRSV, en combinación con el artículo 149.1.1 CE y el contenido de toda la STC 164/2001, materialmente no se distingue entre condiciones básicas y bases (0 legislación básica), porque los artículos que en la LRSV aparecen como básicos en nada se distinguen de aquéllos que regulan las condiciones básicas en aplicación del artículo 149.1.10 CE. Además, de forma a mi juicio esperpéntica, el fundamento jurídico 56 de la STC 164/2001, justifica una "inexistente obligación del legislador de invocar expresamente el título competencial que ampara sus leyes".

En segundo lugar, la STC 164/2001 justifica la constitucionalidad de todas las Disposiciones Generales de la LRSV, así como de sus preceptos sobre la clasificación del suelo y los derechos y deberes de los propietarios, con base en el artículo 149.1.1 ${ }^{\circ} \mathrm{CE}$. Todo ello, en aras de garantizar una pretendida unidad de la propiedad del suelo sin que paradójicamente con ello se pueda alcanzar la imposible igualdad de los propietarios en sus derechos y obligaciones urbanísticos, puesto que éstos, todos ellos, derivan del planeamiento que forzosamente es fuente de desigualdades por los múltiples componentes y variables que debe prever para articular y dar respuesta a los distintos elementos que confluyen en el ámbito objeto de la ordenación urbanística.

Con mayor detalle se va a analizar a continuación la STC 164/2001 y la problemática que la misma suscita en materia de clasificación de suelo. Por ahora, simplemente se apuntan las contradicciones en que incurre la referida Sentencia, que en lugar de crear una doctrina clara partiendo de lo declarado por la STC 61/1997, se limita prácticamente a examinar puntualmente los preceptos de la LRSV, declarando inconstitucionales sólo dos preceptos marginales (artículos 16.1 y 38 de la LRSV) y salvando la constitucionalidad del resto, al dar por supuesto que las expresiones de conceptos urbanísticos empleados en la LRSV como "planeamiento general", "planeamiento de desarrollo", "planes de ordenación territorial", "legislación sectorial", "sistemas generales" y "dotaciones públicas de carácter local" (artículos 9, 11, 14.2 a y b, 15, 17.1, 18.1, 2 y 3 de la LRSV) se deben interpretar de forma tan amplia, que el control constitucional no pueda entrar a delimitar su alcance desde la perspectiva concreta de la igualdad en el ejercicio de la propiedad urbanística. 


\section{4.- Las cuestiones problemáticas de fondo y las claves que laten en la interpretación del artículo $149.1 .1^{\circ} \mathrm{CE}$.}

En primer lugar, contrariamente a lo que se afirmaba en la STC 37/1987 -que anudaba la competencia para establecer las limitaciones y deberes inherentes a la función social de cada tipo de propiedad, con el ente público que ostentase la competencia para regular la materia sobre la que se incide en el contenido de la propiedad-, la STC 61/1997 fija la existencia de un derecho de propiedad llamada urbana o urbanística cuyas condiciones básicas corresponde regular al legislador estatal ex artículo $149.1 .1^{\circ} \mathrm{CE}$.

No obstante, es preciso advertir que contrariamente a lo que ocurre con el derecho de propiedad agraria, como derecho civil natural configurado como realidad evidente, la propiedad urbanística se edifica sobre la propiedad artificial, creada por el planificador urbanístico y, por lo tanto, en nuestro sistema jurídico se parte del hecho incontrovertible de que urbanizar y construir no forman parte del derecho de propiedad con carácter previo a la planificación urbanística, porque el urbanismo constituye una función pública, de tal modo que nadie tiene derecho a transformar el suelo rústico sin plan urbanístico previo, que es quien otorga y reconoce derechos urbanísticos y la futura configuración de la propiedad urbana o urbanística.

Por lo tanto, desde la existencia de un derecho de propiedad urbana o urbanística en el que se cobijan los derechos y deberes urbanísticos, cuyas condiciones básicas compete regular al Estado ex artículo 149.1.1 ${ }^{\circ} \mathrm{CE}$ con la finalidad de igualar los derechos de los propietarios y, por consiguiente, condicionando la competencia autonómica en materia de urbanismo, no queda sino confirmar las siguientes ideas de forma absolutamente clara:

-Si el Estado ostentase algún título competencial que le permitiera incidir en la materia de urbanismo al margen del artículo 149.1.1 ${ }^{\circ} \mathrm{CE}$, en ningún caso tendría que acudir a hacer uso de tal precepto.

-Si se acude al artículo 149.1.10 CE es para justificar el ejercicio de competencias pretendidamente básicas por el Estado en materia de urbanismo (competencias básicas enmascaradas como condiciones básicas del ejercicio del derecho de propiedad urbana), de tal modo que llegan a regularse las distintas clases y subclases de suelo, los derechos y deberes de los propietarios de cada clase de suelo... creando dentro de cada clase de suelo categorías que condicionan limitativamente la legislación autonómica y el planeamiento urbanístico (como sucede, por ejemplo, con las distinciones que realiza la LRSV sobre el suelo urbano consolidado y no consolidado, suelo urbanizable delimitado y no delimitado, o con las distintas categorías de suelo no urbanizable).

En segundo lugar, de acuerdo con la doctrina de la STC 164/2001, la única finalidad que permite al Estado regular los derechos y deberes de los propietarios de las distintas clases de suelo (e instrumentalmente las mismas clases y subclases de suelo) es la de garantizar la igualdad de todos los españoles en el ejercicio del derecho de propiedad denominada urbana. Sin embargo, resulta claro que ninguno de los preceptos amparados en el título competencial ex 149.1.1 ${ }^{\circ} \mathrm{CE}$ (cuyo elemento teleológico es precisamente la consecución de dicha igualdad) garantiza la igualdad de los propietarios del suelo, por dos razones evidentes: 
-En primer lugar, porque, como ya se ha dicho y se reconoce unánimemente, es el planeamiento urbanístico el que atribuye a los propietarios del suelo los derechos urbanísticos, de tal forma, que por mucho que el Estado, por ejemplo, atribuya la condición de suelo residual al suelo urbanizable, si llegado el momento de realizar el planeamiento urbanístico o de su revisión, éste únicamente clasifica todo el suelo del término municipal como suelo urbano y suelo no urbanizable, la igualdad que pretendía la legislación estatal en pro de la liberalización del suelo no tendría ninguna efectividad.

-En segundo lugar, porque al corresponder al Estado, de acuerdo con la jurisprudencia constitucional, la regulación de las condiciones básicas del derecho de propiedad urbana (pero no su régimen completo), el legislador estatal no puede definir los conceptos jurídicosurbanísticos requeridos para materializar los principios generales de la LRSV. Y es precisamente la definición de dichos conceptos urbanísticos, como por ejemplo del suelo urbano consolidado, del solar, del aprovechamiento urbanístico, de las dotaciones públicas locales y sistemas generales... la que determina y condiciona los derechos y deberes urbanísticos de los propietarios, pudiendo éstos resultar muy desiguales en función de la regulación propia de cada Comunidad Autónoma.

En conclusión, difícilmente se puede pretender conseguir con la interpretación del artículo 149.1.1 ${ }^{\circ}$ CE las finalidades que postulan las SSTC 61/1997 y 164/2001. Sin embargo, lo que quizás se pretenda justificar o enmascarar con el artículo 149.1.1 $\mathrm{CE}$ es la interpretación que se defiende por el a la sazón Presidente del TC y el ponente de la STC 164/2001 en su voto particular a la STC 188/2001, donde se afirma que el artículo 149.1.1 ${ }^{\circ}$ CE es "un instrumento constitucional de unidad, que puede conectarse con la idea misma de unidad de la Nación española (art. 2 CE), y permite hacer efectiva en la conciencia de los ciudadanos su parigual condición de españoles. En un Estado social y democrático de Derecho, que es en el que se ha constituido España (art. 1 CE), en el que los derechos fundamentales son el fundamento del orden político y de la paz social (art. $10 \mathrm{CE}$ ), y en el que los poderes públicos tienen la misión (art. 9.2 CE) de hacer real y efectiva la igualdad del individuo y de los grupos en que se integran, y remover los obstáculos que lo impiden"... "El designio de garantizar «la igualdad de todos los españoles en el ejercicio de los derechos y en el cumplimiento de los deberes constitucionales», y habida cuenta de que de derechos y deberes constitucionales se trata, no pueden admitirse grados en la igualación, so pena de que el ejercicio de esos derechos y el cumplimiento de esos deberes pueda llegar a ser realmente distinto en los diversos territorios de España...".

Continua afirmándose con igual tono en el citado voto particular que "ante todo importa destacar que el precepto del art. 149.1.1 ${ }^{\circ}$ CE no es una «regla competencial»... sino una «materia». Y materia de la misma entidad constitucional como tal a las del resto de ellas recogidas en los apartados del art. 149.1 CE. Como tal materia, y no como simple regla competencial, constituye un ámbito de atribución de competencia exclusiva al Estado. Con la particularidad de que, así como en otras materias se incluyen explícita o implícitamente, reglas de acotamiento de la competencia atribuida al Estado respecto de ellas, en ésta no se utilizan elementos conceptuales para esa posible limitación, lo que lleva a la consecuencia de que respecto de esa materia el Estado tiene atribuidas todas las competencias. Con ello no se quiere decir que quede abierto el campo para regular a través del vehículo conceptual de 
las condiciones básicas todo el contenido del derecho de que se trate, pues el régimen normativo del derecho es mucho más amplio que el de la condición básica, de su ejercicio, que solo tiene relación con una parte de ese contenido...".

Finalmente, desde tales postulados se concluye afirmando que "desde un punto de vista lógico y finalístico, y en la tesitura de discernir cuál deba ser el alcance de la idea de regulación (del artículo 149.1.1 $\mathrm{CE}$ ), parece correcto entender que, si el fin con el que se configura la definición de la materia recogida en ese precepto es el de «garantizar la igualdad de todos los españoles en el ejercicio de los derechos y en el cumplimiento de los deberes constitucionales», ese designio finalista solo se puede garantizar si no se diferencia entre un plano normativo y un plano de ejecución, el primero confiado al Estado, y el segundo a las plurales Administraciones de las diversas Comunidades Autónomas, pues este segundo factor de diversidad puede impedir el fin de igualación que es el alma de la condición básica... Desde esa misión de igualación a la que se refiere el art. 149.1.1․ CE no solo no puede subordinarse a los ámbitos materiales de atribución de competencias a las Comunidades Autónomas en sus distintos Estatutos, sino que es un condicionante a respetar por aquéllas, al ejercer las competencias, normativas o de ejecución".

\section{II.- ¿LA REGULACIÓN ESTATAL DE LA CLASIFICACIÓN DEL SUELO COMO PREMISA PARA GARANTIZAR LA IGUALDAD DE TODOS LOS ESPAÑOLES EN EL EJERCICIO DEL DERECHO A LA PROPIEDAD URBANA?}

La Ley 6/1998, de 13 de abril, de Régimen del Suelo y Valoraciones, regula, como es sabido, en su Título II titulado "Régimen urbanístico de la propiedad del suelo", la clasificación del suelo (artículos 7-11) y los derechos y deberes de los propietarios (artículos 12-22). Dos títulos invoca la exposición de motivos a efectos de justificar la regulación de la clasificación del suelo por parte del Estado en los artículos 7 a 11 LRSV: la competencia para fijar las condiciones básicas del derecho de propiedad urbana (artículo 149.1.1 $\mathrm{CE}$ ), y la competencia sobre las bases y coordinación de la planificación general de la actividad económica (artículo 149.1.13 CE).

No obstante, la Disposición Final Única de la LRSV no especifica el concreto título competencial que habilita al Estado para regular los distintos preceptos de la LRSV, sino que en un totum revolutum establece que tienen el carácter de legislación básica en virtud de lo previsto en los artículos $149.1 .13^{\circ}, 18^{\circ}$ y $23^{\circ}$ de la Constitución Española y, en su caso, de condiciones básicas del ejercicio de los derechos a tenor de lo dispuesto por el artículo 149.1.1 ${ }^{\circ}$ del propio Texto Constitucional, los preceptos 1-20, 34, 41, 42, 43, 44.1, disposiciones adicionales segunda, tercera, cuarta y quinta; y disposiciones transitorias primera, segunda, tercera y cuarta, correspondiendo los restantes a la competencia exclusiva del Estado en virtud de los artículos $149.1 .4^{\circ}, 8^{\circ}$ y $18^{\circ} \mathrm{CE}$.

De ahí parece deducirse que la disposición final única de la LRSV le otorga el carácter de legislación básica al entero régimen legal de la clasificación del suelo (a diferencia del TRLS de 1992, cuya regulación sobre la clasificación del suelo tenía, en su mayor parte, mero carácter 
supletorio). De entre los títulos competenciales que invoca para legitimar esa operación, sólo las reglas $1^{\mathrm{a}}$ y $13^{\mathrm{a}}$ del artículo 149.1 CE podrían guardar una pretendida conexión temática con la clasificación del suelo.

En los términos de la exposición de motivos de la LRSV, la clasificación del suelo tiene por objeto evidente "facilitar el aumento de la oferta de suelo, haciendo posible que todo el suelo que todavía no ha sido incorporado al proceso urbano, en el que no concurran razones para su preservación, pueda considerarse como susceptible de ser urbanizado". A este propósito, la categoría de suelo no urbanizable se convierte en la "excepción" (artículo 9 LRSV) y la de suelo urbanizable en la regla general o en la categoría residual, dado que merece tal clasificación y podrá ser, por tanto, objeto de transformación por parte de los propietarios, todo aquel suelo que no sea susceptible de protección en virtud de las causas tasadas que el artículo 9 LRSV establece y no tenga la condición de suelo urbano (artículo 10 LRSV). La Administración actuante, por consiguiente, en principio, no podría declarar no urbanizable un suelo sin justificación alguna. Lo que parece pretenderse es que sólo los terrenos en los que concurran alguna de las causas tasadas enumeradas en el citado artículo 9 LRSV puedan ser declarados como no urbanizables.

De acuerdo con la jurisprudencia constitucional que se analiza a continuación, si el Estado puede aludir y, por consecuencia, condicionar de algún modo el régimen legal de la clasificación del suelo, no es sino por su inmediata vinculación con el derecho de propiedad y a los solos efectos de establecer sus condiciones básicas. No obstante, la finalidad de los artículos 7 a 11 LRSV es posiblemente diseñar las clases de suelo con el propósito de instituir el régimen urbanístico de lo que se llamaría la "propiedad del suelo", por supuesto, sin distinguir el derecho de propiedad de los derechos urbanísticos, o mejor, atribuyendo directamente los derechos urbanísticos al propietario del suelo.

\section{1.- La clasificación tripartita del suelo.}

El artículo 3.2.b) del TRLS de 1992 establecía, con carácter básico, que la competencia urbanística concerniente al planeamiento comprende "dividir el territorio municipal en áreas de suelo urbano, urbanizable, o en su caso apto para urbanizar, y no urbanizable, o clases equivalentes establecidas por la legislación autonómica", distinguiendo, por tanto, las tres clases de suelo tradicionales del derecho urbanístico español. En el mismo sentido, el artículo 9.1 TRLS establecía, con el mismo carácter básico, que "el planeamiento clasificará el territorio en todas o algunas de las siguientes clases: suelo urbano, urbanizable y no urbanizable, o en su caso apto para urbanizar, o, clases equivalentes a los efectos de esta Ley, reguladas por la legislación autonómica".

La vigente LRSV ha mantenido dicha clasificación tripartita en su artículo 7 (al que la confusa disposición final única LRSV atribuye carácter de legislación básica y, en su caso, de condición básica), indicando que a los efectos de dicha Ley, "el suelo se clasifica en urbano, urbanizable y no urbanizable o clases equivalentes reguladas por la legislación urbanística".

La referida clasificación tripartita establecida por el TRLS de 1992 fue impugnada por considerar que se encuadra en la competencia de urbanismo y ordenación del territorio y su contenido no puede quedar salvado por la expresión final "o clases equivalentes establecidas 
por la legislación autonómica". En cuanto al vigente artículo 7 de la LRSV, fue recurrido su inciso final "o clases equivalentes reguladas por la legislación urbanística", cuestionando la competencia estatal para imponer a las Comunidades Autónomas la utilización de una concreta técnica (la clasificación del suelo) para garantizar la igualación básica en el disfrute de la propiedad del suelo.

Ante la alegación de invasión competencial por parte del Estado, el TC amparó la clasificación tripartita del suelo por su carácter instrumental e indispensable respecto de la regulación de las condiciones básicas de ejercicio del derecho de propiedad urbana ex artículo 149.1.1 $\mathrm{CE}$. Consideró que sin esta clasificación previa no sería posible regular condición básica alguna del ejercicio del derecho de propiedad urbana que aquel precepto reserva al Estado, puesto que constituye la premisa, a partir de la cual se fijan tales condiciones básicas, constituyendo dicha clasificación el presupuesto lógico-jurídico para la aplicación del entero sistema de valoraciones a efectos indemnizatorios.

Añadió además, que de la clasificación tripartita del suelo no podía deducirse la prefiguración por el legislador estatal de un concreto modelo urbanístico pues su único contenido imperativo consistía en deferir al titular de la potestad de planeamiento la división del ámbito territorial municipal en todas o algunas de las siguientes hipótesis básicas: suelo consolidado urbanísticamente, suelo apto para el proceso urbanizador y suelo preservado de tal proceso; supuestos básicos a los solos efectos de anudar determinadas facultades dominicales y unos criterios de valoración a su vez básicos del denominado derecho de propiedad urbana. Por tanto, se dispone tan sólo la existencia de tres supuestos básicos por relación con el derecho de propiedad urbana, a fin de distinguir otros tantos regímenes jurídicos fundamentales: suelo en el que no puede darse esta forma de propiedad (delimitación negativa); suelo en el que sí puede establecerse y, por tanto, se encuentra abierto a un proceso de adquisición; y, en fin, suelo en el que ya se ha consolidado su existencia. En opinión del TC "estas hipótesis no son sino consecuencia necesaria del carácter artificial de esta manifestación del dominio, en cuanto producto histórico del hombre, con las peculiaridades que ello entraña" (STC 61/1997, FJ 15.a).

Dicha regulación admite una diversa clasificación del suelo por parte del legislador autonómico, aunque exige equivalencia en las clasificaciones, dado que tal equivalencia es condición básica para la igualdad en los derechos y deberes inherentes a la propiedad urbanística (STC 61/1997, FJ 14.b). Esta conclusión fue ratificada por la STC 164/2001, considerando que la clasificación tripartita del suelo establecida por el artículo 7 LRSV "tiene perfecto encaje en la competencia del Estado ex artículo 149.1.1 ${ }^{\circ}$ CE" (FJ 12), de tal forma que dicho precepto permite al Estado servirse de un instrumento técnico específico (como es la clasificación del suelo) en la medida en que resulta indispensable para definir las "condiciones básicas" de ejercicio del derecho de propiedad" (FJ 13). Con ello, "en nada limita la competencia de las Comunidades Autónomas para fijar y regular, a efectos de planificación y gestión, otras clasificaciones de suelo distintas y superpuestas a las anteriores" (FJ 12).

\section{2.- El suelo urbano}

El artículo 10 del TRLS de 1992 que regulaba con carácter supletorio la definición del suelo urbano en municipios con planeamiento, no fue impugnado en cuanto a su regulación material. No obstante, el TC consideró que la calificación de normas supletorias las reguladoras de una 
materia que, como el urbanismo, todos los Estatutos de Autonomía han asumido como competencia exclusiva, es contraria al artículo 149.3 CE in fine y al orden constitucional de competencias, por cuanto el Estado no puede dictar normas supletorias en materia de urbanismo al carecer de un título competencial específico que así lo legitime (sin que el hecho de ostentar otros títulos competenciales susceptibles de incidir sobre la materia pueda justificar la invocación de la cláusula de supletoriedad del artículo 149.3 in fine de la Constitución Española) (STC 61/1997, FJ 12.c).

Habiendo resucitado, por tanto, la regulación del TRLS de 1976 sobre la clasificación del suelo urbano en aquellas Comunidades Autónomas que no tuvieran una regulación específica al efecto, la LRSV vino a establecer la vigente regulación detallada del suelo urbano, si bien teóricamente debía limitarse a regular dicha clase de suelo con carácter instrumental y en la medida en que fuera un presupuesto necesario para garantizar la igualdad en el ejercicio del denominado derecho a la propiedad urbana ex artículo 149.1.1 ${ }^{\circ} \mathrm{CE}$, de conformidad con lo declarado por la STC 61/1997.

El artículo 8 LRSV sienta los criterios normativos para la clasificación del suelo como urbano, estableciendo que tiene la condición de suelo urbano, a los efectos de dicha Ley:

a) El suelo ya transformado por contar, como mínimo, con acceso rodado, abastecimiento y evacuación de aguas y suministro de energía eléctrica o por estar consolidado por la edificación en la forma y con las características que establezca la legislación urbanística.

b) Los terrenos que en ejecución del planeamiento hayan sido urbanizados de acuerdo con el mismo.

La impugnación de dicho precepto se basó en que, si bien el Estado puede ser competente para la distinción de las clases de suelo a la luz del FJ 15 de la STC 61/1997, no lo es "para fijar los concretos criterios de clasificación de cada clase de suelo; máxime cuando el grado de densidad normativa en la fijación de los criterios es tan concreto como el que muestra el artículo 8 LRSV", tachándolo de desproporcionado para la consecución de la igualdad pretendida por el artículo 149.1.1 $\mathrm{CE}$. Con razón se subrayó que el antecedente del actual artículo 8 LRSV -el artículo 10 TRLS- fue calificado por el propio legislador estatal como supletorio y declarado inconstitucional precisamente por esa naturaleza supletoria, siendo que el mismo contenido normativo que ahora contiene artículo el 8 LRSV se califica como básico. EI TC, no obstante, considerando que la opción estatal por la clasificación tripartita del suelo quedaría privada de su eficacia igualadora si la fijación de los criterios de clasificación en una de las tres clases de suelo fuera plenamente disponible por cada una de las Comunidades Autónomas, señala que "el establecimiento de criterios para la clasificación del suelo actúa como premisa indispensable para la configuración de las condiciones básicas de ejercicio de los tres estatutos jurídicos primarios de la propiedad del suelo", y concluye considerando que la fijación de los criterios de clasificación del suelo urbano por el artículo 8 LRSV, no impone a las Comunidades Autónomas un modelo urbanístico determinado, por las siguientes cuestiones:

- En primer lugar, el artículo 8.a) LRSV en su referencia al suelo "ya transformado" sólo fija criterios mínimos, conocidos frecuentemente como determinantes de la urbanización primaria, pero sin precisar cuándo han de considerarse cumplidos aquellos requisitos mínimos. Permite además que aquellos requisitos se complementen al alza por cada Comunidad Autónoma. 
- En segundo lugar, el mismo artículo 8.a) LRSV se refiere a un hecho (terrenos "consolidados por la edificación"), pero ni impone categorías ni contiene criterios específicos sobre cuándo se da aquella consolidación, ámbito de regulación que queda por entero a cada Comunidad Autónoma.

- La referencia del artículo 8.b) LRSV a los terrenos urbanizados "en ejecución de planeamiento" no se acompaña de criterios específicos sobre cuándo ha de considerarse ejecutado, de tal modo que estas determinaciones caen en la esfera de decisión de las Comunidades Autónomas.

- Finalmente, cada Comunidad Autónoma puede establecer otras clases de suelo (y por tanto, otros criterios de clasificación) para fines distintos de la configuración de las condiciones básicas de ejercicio de la denominada propiedad urbana. Por lo que nada impide que para fines de gestión o de urbanización el legislador autonómico pueda superponer a la clasificación del suelo como urbano otra clasificación distinta y adecuada a los fines urbanísticos de reforma interior o de completa transformación del suelo.

En conclusión, es obvio que el legislador estatal ha mantenido los mismos criterios de clasificación de suelo urbano que se han venido utilizando en el derecho urbanístico tradicional español. No obstante, se ha limitado a recoger los criterios y la terminología tradicional, sin que se tenga competencia para definirla de forma exhaustiva, amparándose con ello en el hecho de que la LRSV sólo fija criterios mínimos (pero sin precisar cuándo han de considerarse cumplidos), no impone categorías ni contiene criterios específicos sobre cuándo se da la consolidación por la edificación, ni sobre cuándo ha de entenderse ejecutado el planeamiento, remitiendo la determinación del contenido de dichos conceptos a la regulación urbanística de cada Comunidad Autónoma e intentando salvar la constitucionalidad del artículo 8 LRSV al considerar que la "limitada" regulación de dicho precepto de ninguna forma predetermina un concreto modelo urbanístico para las Comunidades Autónomas.

¿Cómo se entiende entonces que el TRLS de 1976 y el TRLS de 1992 que regulaban directamente la materia urbanística (y no sólo las pretendidas "condiciones básicas" para garantizar la igualdad en el ejercicio del derecho llamado de propiedad urbana), contuvieran una muy similar regulación de los criterios para la clasificación del suelo urbano (en sus artículos 78 y 10 respectivamente)? ¿Es que aquellos textos legales tampoco imponían un concreto modelo urbanístico, remitiendo, el primero, a la potestad reglamentaria del Gobierno la fijación de dicho modelo, y el segundo, a la eventual legislación autonómica que desplazaría el artículo 10 del TRLS de 1992 por ostentar éste un mero carácter supletorio?

El artículo 8 LRSV sobre la definición del suelo urbano, no distingue entre el suelo urbano consolidado y no consolidado por la urbanización, de tal forma que, atendiendo al carácter mínimo de los criterios empleados por el mismo, que en términos empleados por la STC 164/2001 (FJ 13) no imponen categorías (en relación con el criterio de la consolidación por la edificación del artículo 8.a in fine LRSV), podría deducirse que el legislador autonómico no tiene por qué distinguir las referidas categorías en suelo urbano.

No obstante, el artículo 14 LRSV que regula los deberes de los propietarios de suelo urbano, indirectamente parece que impone tanto al legislador autonómico como al planificador urbanístico la distinción de ambas clases, debido a que los propietarios de suelo urbano consolidado no contribuyen (a diferencia de los propietarios de suelo urbano no consolidado) en la de cesión de aprovechamiento urbanístico, ni siquiera en solares o terrenos ya edificados pero sujetos a obras de rehabilitación (artículo 14.1 LRSV), de la misma forma en que sus antecedentes normativos directos -tanto el artículo 2.1 del Real Decreto-ley 5/1996 como el artículo 2.1 de la Ley 7/1997- establecían expresamente que a los propietarios de 
suelo urbano no incluido en unidades de ejecución correspondía el 100\% del aprovechamiento urbanístico proyectable sobre sus fincas, tanto el fijado directamente por las normas urbanísticas, como el resultante de un instrumento de equidistribución como el área de reparto.

De esta forma, al determinarse por el artículo 14.1 LRSV que todos los propietarios de suelo urbano consolidado por la urbanización de España patrimonializan el 100\% del aprovechamiento urbanístico correspondiente a cada parcela o solar -a diferencia de los propietarios de suelo urbano no consolidado- , y teniendo en cuenta que esa "condición básica" forzosamente se quiere imponer al legislador autonómico, dado que en palabras del Tribunal Constitucional "la exclusión de toda cesión obligatoria de aprovechamiento urbanístico en el suelo urbano consolidado no admite modalización alguna de origen autonómico" (como se ha declarado por la STC 54/2002, FJ 5), parece desprenderse de todo ello que indirectamente la LRSV pretende imponer las categorías de suelo consolidado y no consolidado por la urbanización dentro la clase de suelo urbano, si bien formalmente en el fundamento jurídico 19 de la STC 164/2001 se niega teóricamente dicha imposición.

De forma complementaria, si la distinción de dichas categorías por la legislación estatal no establece un concreto modelo urbanístico, pero sí se impone su previsión por parte de las Comunidades Autónomas a efectos de determinar, entre otras cuestiones, cuales son los terrenos sujetos al deber de cesión del 10\% del aprovechamiento, ¿cuál es el margen que le queda al legislador autonómico en este ámbito? ¿Forzosamente se impone la distinción? ¿El margen que queda es la regulación de los criterios que marquen la distinción entre las categorías de suelo urbano consolidado y no consolidado por la urbanización? En efecto, la STC 164/2001 declaró en su fundamento jurídico 20 que "los criterios de distinción entre suelo urbano consolidado y no consolidado los establece en los límites de la realidad cada Comunidad Autónoma" (lo que se reitera por la STC 54/2002, FJ 5). Si bien, con ello parece atribuir un amplio margen de libertad al legislador autonómico para determinar dichos criterios (limitados únicamente por la realidad), lo cierto es que en la práctica esa libertad podría ser más bien teórica puesto que en la mayoría de las Comunidades Autónomas los criterios para la distinción de ambas categorías de suelo urbano se han regulado de forma bastante similar, entendiendo que constituyen suelo urbano no consolidado aquellos terrenos donde las previsiones de ordenación y su gestión se tienen que llevar a cabo mediante unidades de ejecución o actuaciones integradas.

No obstante, de conformidad con la distribución de competencias articuladas en materia de urbanismo, las Comunidades Autónomas podrían establecer otros criterios distintos para la clasificación del suelo urbano como consolidado y no consolidado por la urbanización, lo que podría conllevar que la regulación estatal sobre los derechos y obligaciones de los propietarios de las distintas categorías de suelo urbano no garantizara su fin igualador de todos los españoles en el ejercicio del denominado derecho a la propiedad urbana, con lo cual el artículo 14 LRSV perdería todo su soporte competencial que se considera residenciado en el artículo $149.1 .1^{\circ} \mathrm{CE}^{10}$.

\footnotetext{
${ }^{10}$ Por ejemplo en la recientemente aprobada Ley 2/2006 de suelo y urbanismo del País Vasco el suelo aparentemente consolidado, podría dejar de serlo siempre en la medida que con el nuevo aprovechamiento del subsuelo pudiera atribuírsele la ordenación una edificabilidad urbanística ponderada superior respecto a la previa existente. Recuérdese que su artículo 11.3 establece que: "Los terrenos clasificados como suelo urbano conforme a lo dispuesto en el presente artículo deberán ser adscritos a las siguientes categorías: a) Suelo urbano consolidado, integrado por los terrenos a que se refiere el apartado 1 del presente artículo, cuando estén urbanizados o tengan la condición de solares y no se encuentren comprendidos en el apartado siguiente. b) Suelo urbano no consolidado, que comprende los terrenos que la ordenación urbanística adscriba a esta clase de suelo por concurrir alguna de las siguientes circunstancias: 1.- Carecer de urbanización consolidada por: a) No comprender la urbanización existente las
} 
Por su parte, el hecho de que a los propietarios de suelo urbano consolidado no se les imponga el deber de cesión del $10 \%$ a diferencia de los propietarios de suelo urbano no consolidado, no constituye, en términos del TC, "discriminación alguna entre personas y por circunstancias subjetivas, que es lo prohibido por el art. 14 CE", sino que se trata de distintas regulaciones abstractas del derecho de propiedad de acuerdo con la STC 164/2001 (FJ 20). Tampoco constituye la ausencia del deber de cesión en suelo urbano consolidado "una opción estatal por la expropiación forzosa como instrumento de obtención de suelo dotacional", porque según el Tribunal Constitucional, el artículo 33.3 CE prohíbe la apropiación pública del derecho de propiedad urbana sin indemnización, de modo que "no sería el art. 14.1. LRSV sino a lo sumo el art. 33.3 CE quien impondría a los municipios la obtención de suelo dotacional mediante expropiación" (STC 164/2001, FJ 20).

Por otra parte, desde una perspectiva competencial, "para la participación de la comunidad en las plusvalías urbanísticas (mediante la regulación de las condiciones básicas de ejercicio del derecho de propiedad) el Estado dispone de un amplio margen de configuración"; "el art. 47 CE no impide, en este sentido, que la participación en las plusvalías se concentre en determinadas clases de suelo. De esta forma, la hipotética existencia de plusvalías urbanísticas en suelo urbano consolidado... no excluye a priori una norma estatal que alivie de cesiones de aprovechamiento a sus propietarios" (STC 164/2001, FJ 20, y STC 54/2002, FJ 4). Por todo ello, concluye el TC que "la regulación que del derecho de propiedad del suelo establece el art. 14.1 LRSV (urbano consolidado) no impone concretas técnicas urbanísticas" (STC 164/2001, FJ 20).

Ante dicha argumentación, cabría preguntarse ¿qué es (sino una concreta técnica urbanística) la ausencia del deber de cesión de aprovechamiento en suelo urbano consolidado? ¿Se puede considerar acaso como una condición básica para garantizar el régimen uniforme en el disfrute de la denominada propiedad urbana? ¿Pero cómo se garantiza dicho régimen uniforme cuando las cargas para completar la urbanización de los terrenos de suelo urbano consolidado (artículo 14.1 LRSV) pueden ser muy diferentes de un ámbito a otro?

Las rotundas afirmaciones livianamente argumentadas por el TC dejan numerosas lagunas e incongruencias que denotan el escaso respaldo jurídico competencial que ampara la amplia intervención estatal en este ámbito urbanístico. Porque quizá lo que se pretende es establecer unas bases en materia del régimen urbanístico del suelo urbano, y para ello se pretende anudar directamente al régimen de propiedad del suelo, los derechos urbanísticos que configura el planeamiento, y al mismo tiempo, establecer el régimen jurídico del aprovechamiento en las distintas categorías de suelo urbano que indirectamente se imponen, pese a que se siga apostando por una teórica libertad de las Comunidades Autónomas basada en la idea de que podrán distinguir entre suelo urbano consolidado y no consolidado, si bien en la práctica no tienen más remedio por ahora que acomodarse al régimen establecido en el ámbito estatal. De cualquier modo, que la regulación actual es insostenible

dotaciones, servicios e infraestructuras precisos exigidos por la ordenación urbanística o carecer unos y otros de la proporción, las dimensiones o las características adecuadas exigidas por la misma para servir a la edificación que sobre ellos exista o se hubiera de construir. b) Precisar la urbanización existente de renovación, mejora o rehabilitación que deba ser realizada mediante la transformación urbanística derivada de la reordenación o renovación urbana, incluidas las dirigidas a establecimiento de dotaciones. 2.- Atribuirle la ordenación una edificabilidad urbanística ponderada superior respecto a la previa existente." 
desde la lógica constitucional de igualdad lo probará la futura legislación estatal que suprima, desde idéntica perspectiva jurídica sustentada en el artículo 149.1.1 CE, parámetros de igualdad sustentados en la propiedad urbana o urbanística, actualmente vigentes.

\section{3.- El suelo no urbanizable}

Los criterios para la clasificación del suelo como no urbanizable han sufrido en los últimos años grandes variaciones. El artículo 12 del TRLS de 1992 mantenía, con carácter supletorio, la regulación anterior del suelo no urbanizable (establecida por el artículo 80 TRLS de 1976), de tal suerte que le atribuía a esta clase de suelo la condición de suelo residual, al constituir suelo no urbanizable "los terrenos que el planeamiento general no incluya en ninguna de las clases de suelo anteriores $y$, en particular, los espacios que dicho planeamiento determine para otorgarles una especial protección, en razón de su excepcional valor agrícola, forestal o ganadero, de las posibilidades de explotación de sus recursos naturales, de sus valores paisajísticos, históricos o culturales, o para la defensa de la fauna, la flora o el equilibrio ecológico" (artículo 12 TRLS de 1992).

Si bien este precepto fue declarado inconstitucional por la STC 61/1997 debido a su carácter supletorio, posteriormente el legislador estatal ha vuelto a regular los criterios para clasificar el suelo como no urbanizable, esta vez con carácter básico o de condición básica, y realizando un cambio sustancial en relación con el régimen anterior. $Y$ es que, con la idea de facilitar la oferta de suelo, la LRSV posibilita la urbanización en todo el suelo "en el que no concurran razones para su preservación", de acuerdo con lo dispuesto en el planeamiento y en la legislación territorial o sectorial, de tal modo que en adelante, el suelo residual ya no será, como antes, el suelo rústico o no urbanizable, sino el urbanizable, que se define negativamente como aquel que "no tenga la condición de urbano o de no urbanizable".

De modo que el Plan, además de identificar el suelo urbano, ha de delimitar y precisar también concreta y positivamente cuál es el suelo rústico, porque todo lo demás sería urbanizable. Pero ese mismo planificador no tendría libertad para definir el suelo rústico con sus propios criterios -por imperativo de la legislación urbanística estatal-, sino que sólo puede hacerlo en atención a la existencia de unos valores que plasma genéricamente la Ley estatal y cuya concreción el planificador debe justificar y motivar, lo que significa que debe explicar qué valores de los previstos en la Ley están presentes para excluir un determinado suelo del proceso urbanizador, porque de no existir esos valores sustantivos positivos, el suelo será, como regla general, urbanizable.

La LRSV establece en su actual artículo 9 (cuya redacción original ha sido modificada por el artículo 1.1. del Real Decreto-ley 4/2000 y de la Ley 10/2003) que tendrán la condición de suelo no urbanizable, a los efectos de dicha Ley, los terrenos en que concurra alguna de las circunstancias siguientes:

- "Que deban incluirse en esta clase por estar sometidos a algún régimen especial de protección incompatible con su transformación de acuerdo con los planes de ordenación territorial o la legislación sectorial, en razón de sus valores paisajísticos, históricos, arqueológicos, científicos, ambientales o culturales, de riesgos naturales acreditados en el 
planeamiento sectorial, o en función de su sujeción a limitaciones o servidumbres para la protección del dominio público.

- Que el planeamiento general considere necesario preservar por los valores a que se ha hecho referencia en el párrafo anterior, por su valor agrícola, forestal, ganadero o por sus riquezas naturales, así como aquellos otros que considere inadecuados para el desarrollo urbano, bien por imperativo del principio de utilización racional de los recursos naturales, bien de acuerdo con criterios objetivos de carácter territorial o urbanístico establecidos por la normativa urbanística".

La actual redacción del apartado segundo de este artículo procede del artículo 1.1. de la Ley 10/2003, de 20 de mayo, de medidas urgentes de liberalización del sector inmobiliario, que sustituye la anterior redacción del Real Decreto-ley 4/2000, de 23 de junio, del mismo nombre.

La norma parte, como se ha indicado previamente, de que el suelo no urbanizable ya es un suelo residual porque para clasificar un terreno como tal es preciso que en él concurra alguna de las circunstancias que enumera el precepto. La regla primera (cuya redacción sigue siendo la primitiva de 1998) parece imponer un inicial criterio reglado (los terrenos "que deban incluirse...") frente a otro más discrecional de la regla segunda (los terrenos que el planeamiento "...considere necesario preservar". Por tanto, el Plan debe clasificar un terreno como suelo no urbanizable cuando se den las circunstancias regladas del apartado primero del artículo 9 LRSV y puede clasificar también un terreno como no urbanizable con justificación porque haya unos valores a preservar o porque el propio planeamiento los considere inadecuados para su desarrollo urbano, de acuerdo con el principio de utilización racional de los recursos naturales, así como con los criterios objetivos de carácter territorial o urbanístico establecidos por la legislación urbanística autonómica.

Como consecuencia de la reforma operada en la LRSV por el Real Decreto-ley 4/2000, de 23 de junio, de medidas urgentes de liberalización en el sector inmobiliario y los transportes, se suprimió en lo relativo a la clase de suelo no urbanizable, el inciso "así como aquellos otros que considere inadecuados para un desarrollo urbano", limitando la facultad municipal de excluir del proceso urbanizador los terrenos que el propio municipio considerase inadecuados para su desarrollo urbano. La reforma se justificó por la exposición de motivos en la necesidad de obtener suelo y corregir rigideces en ese mercado.

El Real Decreto-ley se tramitó después como Proyecto de Ley, estuvo tres años en hibernación en sede parlamentaria, hasta que el 20 de mayo de 2003 viera la luz la Ley 10/2003, que es el resultado de dicho proceso y sustituía al Real Decreto-ley 4/2000 añadiendo al párrafo segundo del artículo 9 LRSV el inciso "así como aquellos otros que considere inadecuados para el desarrollo urbano, bien por imperativo del principio de utilización racional de los recursos naturales, bien de acuerdo con criterios objetivos de carácter territorial o urbanístico establecidos por la normativa urbanística".

Entre el largo período que media entre el verano de 2000 y la primavera de 2003 se produjo un hecho que tuvo una influencia significativa en la versión final del artículo 9 establecida por la Ley 10/2003. Ese hecho fue la STC 164/2001, que resuelve como es sabido, el recurso de inconstitucionalidad interpuesto contra determinados preceptos de la LRSV. 
EI TC analizó la primera versión del artículo 9 LRSV, sin enfrentarse a la versión reformada por el artículo 1.1 del Real Decreto-ley 4/2000. No obstante, lo declarado sobre el criterio de la inadecuación para el desarrollo urbano, indirectamente prejuzgaba la eventual inconstitucionalidad de la supresión de dicho criterio por el artículo 1.1. del Real Decreto-Ley $4 / 2000$.

La inicial redacción del precepto establecía dos criterios directos para la clasificación del suelo como no urbanizable: que el suelo fuera incompatible con su transformación urbana y que fuese inadecuado para un desarrollo urbano. Ambos criterios fueron impugnados por considerar que suponían una intromisión del legislador estatal en materia propiamente urbanística, así como la predeterminación de un concreto modelo urbanístico y territorial.

EI TC consideró, sin embargo, que estos dos criterios mínimos o elementales de clasificación sirven como criterios mínimos de igualación de todos los propietarios de suelo. Por lo tanto, tal fin igualador, a juicio del TC, atrae en principio la regulación del artículo 9 LRSV a la esfera competencial del Estado ex artículo 149.1.1ํ $\mathrm{CE}$. En consecuencia, esa regulación instrumental entendía que no incide de forma ilegítima en las competencias urbanísticas de las Comunidades Autónomas en cuanto "la suma de los dos criterios de clasificación contenidos en el art. 9 LRSV (incompatibilidad e inadecuación para el desarrollo urbano) permite identificar un amplio margen de regulación para cada Comunidad Autónoma", y de ello se deduce su conformidad constitucional (STC 164/2001, FJ 14).

En cuanto al primer criterio, cuya redacción inicial se ha mantenido hasta la fecha, el TC añade que "la incompatibilidad con la transformación (art. 9.1 LRSV) no la define la propia Ley, sino que provendrá de los regímenes especiales de protección establecidos por la legislación sectorial o el planeamiento territorial (del Estado o de la Comunidad Autónoma, dependiendo de la materia competencial o sector en que se funde el régimen especial de protección)... la efectiva clasificación del suelo como no urbanizable no deriva automática e inmediatamente de la fijación de un régimen de especial protección sino que depende, en todo caso, de que el órgano público competente para la clasificación del suelo efectivamente concluya que el régimen especial de protección previamente establecido exige la clasificación del suelo como no urbanizable". En coherencia con ello, el TC niega "todo carácter restrictivo al listado de valores y fines determinantes de regímenes especiales de protección. Los distintos regímenes de protección traen causa de los distintos títulos competenciales del Estado y de las Comunidades Autónomas. Será entonces el titular de cada competencia el que identifique y valore la importancia de un fin u objeto para establecer un régimen especial de protección. En este sentido debe entenderse que la enumeración de valores y fines del art. 9.1 LRSV sólo tiene carácter ejemplificativo" (STC 164/2001, FJ 14.a).

Por lo que respecta a la segunda regla para la clasificación del suelo como no urbanizable, la redacción inicial del artículo 9 LRSV contemplaba como criterio de clasificación, la inadecuación de los terrenos para un desarrollo urbano. El TC precisó que el juicio relativo a la inadecuación "le corresponde, en todo caso, al órgano competente para la clasificación. La deficiente adecuación puede traer causa de valores o fines que hagan necesaria la preservación del suelo (el propio art. 9.2 LRSV enuncia los valores agrícola, forestal, ganadero, así como la riqueza natural) o de otras circunstancias. Al planeamiento corresponde 
establecer... los criterios sobre cuándo un terreno es adecuado, o no, para un desarrollo urbano, remitiendo de esta forma la clasificación del suelo al planificador urbanístico. Por ello, en forma alguna se puede considerar que el art. 9.2 LRSV imponga un concreto modelo urbanístico y territorial" (STC 164/2001, FJ 14.b).

No obstante, una vez suprimida por el Real Decreto-ley 4/2000 esta segunda regla que permitía al titular de la competencia urbanística clasificar suelo no urbanizable por considerarlo inadecuado para el desarrollo urbano, la pregunta que surgía de forma inmediata era si la LRSV imponía un concreto modelo urbanístico y territorial incompatible con el sistema de distribución de competencias.

Es lo que parecía insinuar la STC 164/2001, al declarar que "es la concurrencia de los dos criterios del art. 9.2 LRSV, en la concreta redacción de 1998, lo que lleva a rechazar el reproche de inconstitucionalidad". Por lo que si bien la STC 164/2001 no afrontó la reforma del Real Decreto-ley 4/2000, daba ocasión de replantear el tema que estaba paralizado en el Congreso.

Al desbloquearse el Proyecto de Ley derivado del Real Decreto-ley 4/2000 y que posteriormente se convirtió en la Ley 10/2003, el resultado es el texto actual del artículo 9.2 LRSV que vuelve a contemplar el inciso relativo a la "inadecuación para el desarrollo urbano" como criterio de la clasificación de un terreno como suelo no urbanizable, si bien añade las razones que habrá de aducir el planificador para motivar la "inadecuación" del terreno y que consisten en "el principio de utilización racional de los recursos naturales" o en "criterios objetivos de carácter territorial o urbanístico establecidos por la normativa urbanística".

La previsión del criterio de la inadecuación para el desarrollo urbano, parece más respetuoso no sólo con las competencias autonómicas en materia de ordenación del territorio y urbanismo, sino también con el principio de autonomía local y, en concreto, con la opción política del tipo de pueblo o de ciudad que se pretenda construir.

Ahora bien, se ha puesto de relieve que la reforma de 2003 poco se acomoda a su justificación, puesto que la exposición de motivos de la Ley 10/2003 sigue hablando de que las medidas que se adoptan "pretenden corregir las rigideces advertidas en el mercado como consecuencia del fuerte crecimiento de la demanda y la incidencia en los productos inmobiliarios del precio del suelo, condicionada a su vez por la escasez de suelo urbanizable y urbanizado, según los casos. En consecuencia, la reforma que se introduce habrá de incrementar la oferta del suelo al introducir flexibilidad en aquellas previsiones normativas en vigor que pudieran limitarla". "En esta dirección se orientan la mayor objetivización de la clasificación del suelo no urbanizable...". Como señala MARTíN REBOLLO, con razón, "es difícil entender estas palabras cuando resulta que la Ley lo que hace es posibilitar un mayor margen para la clasificación de suelo no urbanizable, lo que nada tiene que ver con el incremento de la oferta de suelo, sino con la protección del entorno y con la flexibilización de los criterios para la clasificación de suelo como no urbanizable" (Leyes Administrativas, Aranzadi, 2006, p. 2194).

Finalmente, es preciso destacar que la STC 164/2001 impone una interpretación conforme a la Constitución en relación con las referencias del artículo 9 LRSV a los "planes de ordenación territorial", "legislación sectorial", "planeamiento general" y "planeamiento sectorial". El TC 
considera que si bien pudieran ser interpretados dichos términos "como la imposición de concretos instrumentos urbanísticos a las Comunidades Autónomas, de lo que resultaría una vulneración del orden constitucional de competencias, también permiten una interpretación conforme con la Constitución", en el sentido de que "el art. 9.1 LRSV traslada al ámbito de la clasificación del suelo, y a los efectos de esta Ley, lo ya dispuesto en otros actos jurídicos que tienen por fin la protección de ciertos bienes naturales o culturales; se puede entender, entonces, que la referencia a la "legislación sectorial", "planes de ordenación territorial", y "planeamiento sectorial" tienen únicamente valor orientativo y ejemplificativo, pues lo único propiamente relevante es... que los terrenos estén sometidos a algún régimen especial de protección, venga ese régimen especial dispuesto en leyes, planes, proyectos, catálogos o cualesquiera otros actos jurídicos". Tampoco "puede considerarse que la mención del art. 9.2. LRSV al "planeamiento general" vulnere las competencias urbanísticas de las Comunidades Autónomas", siendo posible interpretar que "el planeamiento general es, en el art. 9.2 LRSV, aquel instrumento de ordenación o planificación urbanística que conforme a la legislación urbanística de cada Comunidad Autónoma puede o debe clasificar el suelo de las ciudades y dotar de un contenido preciso a los derechos de propiedad urbana y permitir su efectivo disfrute. Así interpretada, la alusión al "planeamiento general" en el art. 9.2 LRSV es conforme con el orden constitucional de competencias" (STC 164/2001, FJ 14).

Como conclusión de la regulación estatal sobre los criterios para clasificar suelo como no urbanizable, así como de la doctrina constitucional que ha considerado constitucional dicha regulación, cabe destacar que si desde una interpretación sistemática de los artículos 7-11, 13 y siguientes de la LRSV, al legislador autonómico no le restara espacio apreciable alguno para fijar otros criterios sustantivos desde la materia urbanística, en pro de la no urbanización de los terrenos, se plantearían problemas de inconstitucionalidad. Sin embargo, si el artículo 9 LRSV permite "identificar un amplio margen de regulación para cada Comunidad Autónoma" (STC 164/2001, FJ 14), podría justificarse su constitucionalidad. Cuestión distinta es que ese amplio margen lo ostente junto con la Administración autonómica en el ámbito normativo, también la Administración urbanística en el ámbito ejecutivo.

No obstante, si el artículo 9 LRSV, más que establecer "criterios mínimos" (acerca de la incompatibilidad e inadecuación) como parece ver la STC 164/2001, intentara cerrar el concepto legal de suelo no urbanizable, su contenido sería incompatible con las competencias de las Comunidades Autónomas en materia de urbanismo. Por lo tanto, el artículo 9 LRSV no puede predeterminar el entero modelo urbanístico, aunque prima facie delimite el régimen legal de clasificación del suelo no urbanizable a efectos urbanísticos. A este propósito, el tema de fondo y de carácter previo es que el Estado carece de competencias ex artículo 149.1.1으 $\mathrm{CE}$ para cerrar el régimen jurídico en materia de urbanismo, es decir, del suelo urbano, urbanizable y no urbanizable; y por ello, que desde la misma exposición de motivos se invoca la regla $13^{a}$ del artículo 149.1 CE, con la pretensión de ofrecer la cobertura constitucional que en cada caso se estime necesaria, desde las bases de la planificación general de la actividad económica.

En suma, la STC 164/2001 no realiza una reflexión más profunda para enfrentarse a la cuestión de los criterios de clasificación de suelo a la luz de la competencia estatal ex artículo 149.1.1 ${ }^{\circ} \mathrm{CE}$, a partir de la doctrina de la STC 61/1997. Se pone el acento en el criterio de la "predeterminación del modelo urbanístico", sin indagar primero hasta qué punto puede el Estado, con base en la competencia del artículo 149.1.1 $\mathrm{CE}$, establecer las normas 
impugnadas. Además, de la doctrina de la STC 164/2001 se deduce que en la medida en que a las Comunidades Autónomas les reste un espacio de libertad, se habría respetado su competencia de desarrollo de las bases estatales, que se equiparan a las condiciones básicas que garanticen la igualdad, sin reparar, por otra parte, en si ese margen es legislativo (a partir de la competencia urbanística), o se sitúa en el plano administrativo o de elaboración y ejecución del planeamiento.

Destaca por consiguiente el enjuiciamiento individualizado de los artículos 7-11 LRSV, y no en su entero conjunto, y sus conexiones con las disposiciones transitorias, lo que habría permitido calibrar, en su justa medida, los efectos del régimen dispuesto, asimilado en realidad como se ha indicado a la legislación básica, en lugar de a las normas portadoras de las "condiciones básicas" a que se refiere el título habilitante del artículo 149.1.1 CE.

\section{4.- El suelo urbanizable.}

El artículo 11 del TRLS de 1992, de carácter supletorio, mantenía el carácter residual del suelo urbanizable, constituido por los terrenos que el Plan General Municipal declarara adecuados, en principio, para ser urbanizados. Dicho precepto distinguía dentro del suelo urbanizable, las categorías de suelo programado, que como se sabe se integraba del suelo cuyo planeamiento parcial debiera ser aprobado en el plazo previsto en el programa del propio plan, y de suelo no programado, es decir, el que sólo podía ser objeto de urbanización mediante la aprobación de programas de actuación urbanística (artículo 11.2 TRLS de 1992).

Asimismo, junto al suelo urbanizable regulaba el suelo apto para urbanizar por las normas subsidiarias de planeamiento, que lo equiparaba al suelo urbanizable programado excepto a los efectos de la necesidad de programación y del régimen de utilización del suelo (artículo 11.3 TRLS de 1992). Asimismo, el suelo apto para urbanizar se equiparaba al suelo urbanizable programado en cuanto a la valoración del suelo, los supuestos expropiatorios y la obtención de terrenos dotacionales (artículo 11.4 TRLS de 1992).

Este último párrafo del artículo 11 del TRLS de 1992 -el único que tenía carácter básico- fue impugnado ante el TC por considerar que su carácter básico no respetaba el orden constitucional de competencias. Como consecuencia de dicha impugnación el TC lo declaró inconstitucional por la STC 61/1997 debido a que su presupuesto de hecho (las categorías mismas del suelo programado y los instrumentos del planeamiento utilizables) así como algunas de sus consecuencias jurídicas (la obtención de terrenos dotacionales y supuestos expropiatorios, salvo los que se refieran al incumplimiento de las condiciones básicas) podían existir o no, de acuerdo con la libre decisión del legislador autonómico. El TC declaró al respecto que las "clases de suelo e instrumentos de planeamiento -apto para urbanizar por normas subsidiarias, y urbanizable programado- no son sino expresión de una mera opción de la política urbanística y para cuya configuración o enunciado carece de título competencial el Estado" (STC 61/1997, FJ 15 b).

Y es que el artículo 11.4 del TRLS de 1992 no se limitaba a enunciar los grandes supuestos en que pueda encontrarse el suelo a efectos de anudarle, por referencia, unas condiciones básicas de ejercicio del denominado derecho de propiedad urbana o urbanística, sino que "determinaba una asimilación entre dos clases de suelo, el apto para urbanizar por normas subsidiarias y el urbanizable programado, en relación con las causas de expropiación, de 
valoración del suelo y de obtención de terrenos dotacionales. De este modo, dicho precepto prefiguraba, siquiera sea indirectamente, un concreto modelo urbanístico" (STC 61/1997, FJ $15 \mathrm{~b})$.

EI TC añadió que si bien el legislador estatal, en virtud de las competencias reconocidas en las reglas $1^{\mathrm{a}}$ y $18^{\mathrm{a}}$ del artículo $149.1 \mathrm{CE}$, puede determinar la aplicación y equiparación de ciertos criterios de valoración según el estado en que se encuentre el proceso de urbanización, sólo lo puede hacer en sus líneas generales, sin pretensiones definitorias, y al simple objeto de fijar algunas de las consecuencias jurídicas que pueden llevar aparejados.

El resto de los apartados del artículo 11 del TRLS de 1992 relativos a la clasificación del suelo urbanizable o apto para urbanizar también fueron declarados inconstitucionales pero, en este caso, por su carácter supletorio. Posteriormente, y como ya se ha indicado, la LRSV de 1998 ha propuesto un cambio sustancial en la regulación del suelo urbanizable, al haberle atribuido el carácter de "suelo residual". Al respecto, el artículo 10 LRSV dispone con carácter de "condiciones básicas" que "el suelo que, a los efectos de esta Ley, no tenga la condición de urbano o de no urbanizable, tendrá la consideración de suelo urbanizable, y podrá ser objeto de transformación en los términos establecidos en la legislación urbanística y en el planeamiento aplicable".

En respuesta a su impugnación, el TC rechazó que este precepto contuviera una opción urbanística primaria (la opción del suelo urbanizable como categoría residual de suelo) tal como le imputaban los recurrentes. En tal sentido, argumentaba el TC que "allí donde la Comunidad Autónoma disfrute de un amplio poder decisorio para la clasificación del suelo como urbano o no urbanizable la clasificación legal residual (urbanizable) ni vacía ni impide el ejercicio de las competencias urbanísticas autonómicas" (STC 164/2001, FJ 15). Por lo tanto, si se confirma el amplio margen decisorio autonómico para la clasificación del suelo urbano (artículo 8 LRSV) y para la clasificación del suelo como no urbanizable (artículo 9 LRSV), el artículo 10 LRSV no impondría "a las Comunidades Autónomas, ni cómo ni cuándo el suelo urbanizable debe pasar a ser ciudad", puesto que la referencia a que la transformación del suelo urbanizable tendrá lugar "en los términos establecidos en la legislación urbanística y planeamiento aplicable" remite a lo que cada Comunidad Autónoma disponga. "Por ello concluye el TC- no puede considerarse que el art. 10 LRSV vulnere las competencias urbanísticas autonómicas" (STC 164/2001, FJ 15).

En relación con dicha doctrina, la cuestión más débilmente resuelta en el examen individualizado de los artículos 7-11 LRSV y concordantes, acaso resida en la cobertura del título estatal del artículo 149.1.1 ${ }^{\circ} \mathrm{CE}$, para fijar, como lo hace la LRSV, los criterios sustantivos de clasificación del suelo, siendo como es una nueva cuestión, no abordada expresamente por la STC 61/1997 y bajo cuyos postulados resulta de difícil justificación. El problema fundamental no descansa en reconocer que el cuándo y el cómo quedan a disposición autonómica, sino si los criterios para fijar el "cuánto" quedan a su disposición, y también si con fundamento en el artículo $149.1 .1^{\circ} \mathrm{CE}$ el Estado puede establecer tales criterios.

Finalmente, en esta clase de suelo urbanizable, aunque así no se disponga expresamente en el artículo 10 LRSV, parece que se quiere seguir manteniendo la subdivisión entre el suelo urbanizable materialmente programado o delimitado, en el sentido de suelo respecto del que se ha completado ya el proceso de decisiones sucesivas preciso para legitimar $y$, por tanto, desencadenar la actividad de ejecución (urbanización y edificación), y el suelo urbanizable 
materialmente no programado o no delimitado, en el sentido de suelo respecto del que aún no se ha completado el aludido proceso decisional (en cuanto a la delimitación del sector o, en todo caso, ámbito de actuación de transformación mediante la urbanización y la definición de las condiciones urbanísticas pertinentes).

Todo ello se deduce de la LRSV, puesto que diferencia, a la hora de regular los derechos de los propietarios y, más concretamente, el derecho a promover la transformación mediante la urbanización, entre el suelo de esta clase en el que se hayan delimitado ámbitos o sectores con vistas a su desarrollo inmediato (artículo 17.1 LRSV) y aquel respecto del cual tales determinaciones no han sido aún establecidas. Esta diferenciación es trascendente pues de ella depende la posibilidad o no del ejercicio sin más del derecho a promover la transformación del suelo mediante la urbanización (artículo 16 LRSV, cuyo párrafo primero fue declarado inconstitucional por la STC 164/2001, y su redacción actual procede del artículo 1.3 de la Ley 10/2003, de 20 de mayo, de medidas urgentes de liberalización del sector inmobiliario).

\section{5.- Conclusiones en relación con las clases de suelo}

La LRSV continúa la tradición del ordenamiento español de articulación del régimen de clasificación urbanística del suelo, es decir, su división en clases por razón del destino urbanístico. Para ello aprovecha la admisión por la STC 61/1997 de ordenar una legislación estatal dirigida a establecer el marco de la materia urbanística con base en el artículo 149.1.10 CE y para hacer referencia a las técnicas urbanísticas cuando ello sea estrictamente indispensable para el cumplimiento de sus objetivos. En la medida que la regulación de la clasificación fuese acabada o lo suficientemente precisa -con pretensión además, de hacer de la inclusión de concretos terrenos en las diferentes clases un acto reglado- y no se dejase espacio mínimamente significativo para la legislación autonómica urbanística, la regulación estatal sería inconstitucional.

En un segundo nivel, quizá no sea necesario determinar tanto si los artículos 7-11 LRSV dejan o no algún espacio de libertad a las Comunidades Autónomas (que sin duda lo dejan, aunque lo sea en aspectos formales o complementarios de aplicación del régimen legal estatal), sino cómo se justifica que el artículo 149.1.1 ${ }^{\circ} \mathrm{CE}$ permita el cuasi-agotamiento de los criterios sustantivos de lo que sea cada clase de suelo.

No es ya sólo que el régimen jurídico de la clasificación del suelo no se justifique, en sí mismo considerado, en las condiciones básicas, esto es, que no responda por su acabada regulación y la materia objeto de normación a la finalidad que dice perseguir (la garantía de una igualdad básica mediante unas condiciones básicas), o, que tal clasificación exceda en mucho de lo que pueda considerarse como un "presupuesto para el derecho de propiedad", sino que, a la complitud del régimen legal de la clasificación del suelo, le pueda seguir una también notoria extralimitación en la regulación de los derechos y deberes de los propietarios del suelo, sin distinguir claramente la "propiedad" y los "derechos urbanísticos" que reconoce el planeamiento. 
Por supuesto, la regulación de los artículos 7-11 LRSV no puede encontrar amparo en la competencia exclusiva del Estado sobre "las bases y la coordinación de la planificación general de la actividad económica" (artículo 149.1.13 CE), puesto que, a la luz de la doctrina constitucional, cabe apreciar que el referido título no da soporte alguno al Estado para fijar reglas relativas al derecho de propiedad y al sistema de garantías; sí en cambio para incidir, en su caso, sobre la ordenación de la ciudad en sentido amplio. En efecto, señala el TC que "cuando el Estado se apoya en un título tan genérico como es el de bases y coordinación de la planificación de la actividad económica frente a la competencia exclusiva... de las Comunidades Autónomas, no puede, salvo cualificadas excepciones, continuar operando con todos los instrumentos de los que disponía con anterioridad a la descentralización del mismo... Tal inteligencia restrictiva del art. 149.1.13 $\mathrm{CE}$ cuando afecta a la competencia urbanística de las Comunidades Autónomas ha de verse complementada además por una interpretación finalista o teleológica, de modo que tan sólo aquellas normas básicas que respondan efectiva y estrictamente a la planificación general de la actividad económica podrían encontrar cobijo en el referido título, que impide la producción de normas que, aunque relacionadas con esa planificación general, no guarden esa inmediata y directa relación con la dirección de la economía" (STC 61/1997, FJ 36).

Aunque la definición de las clases de suelo termine por repercutir en la economía en sentido amplio o general, como cualquier otra actividad relevante desde el punto de vista económico, no obedece, efectiva y estrictamente, a la planificación general de la economía, sino que tiene por objeto inmediato y directo el establecimiento de un llamado régimen urbanístico de aprovechamiento, trasformación o conservación del suelo, y no necesariamente de su régimen de propiedad, puesto que como reiteradamente se ha señalado a lo largo de este trabajo, resulta preciso distinguir siempre entre propiedad del suelo -que permite su uso, disfrute o disposición- y los concretos derechos urbanísticos que genera en exclusiva en nuestro ordenamiento jurídico el planeamiento.

\section{III.- A MODO DE EPÍLOGO}

De conformidad con las ideas desarrolladas en este trabajo, la pregunta a la que debe responderse en clave constitucional-urbanística es la de si en nuestro ordenamiento jurídico del derecho de propiedad nacen los derechos urbanísticos o si, por el contrario, los derechos urbanísticos los otorga siempre el planeamiento elaborado y aprobado por los poderes públicos $^{11}$. En respuesta a esta pregunta, si en materia urbanística se distingue entre el derecho de propiedad y los derechos urbanísticos, el artículo 149.1.1 CE —con base sólo en el

\footnotetext{
11 Al respecto pueden verse las brillantes conclusiones de J. GARCÍA-BELLIDO GARCÍA DE DIEGO que, a este propósito, se expresaba en los siguientes términos: “¿Cabe suponer que el Estado habrá de darse cuenta de que el único cordón umbilical que le sigue ligando y legitimando para legislar sobre el urbanismo es la propiedad civil y que ésta no tiene nada que ver con la actividad urbanizadora, debiendo dejárselo in totum a la entera competencia de las Comunidades Autónomas? (...) Vid "La excepcional estructura del urbanismo español en el contexto europeo", Documentación Administrativa, núms. 252-253, septiembre 1998-abril 1999, p. 78. Puede verse asimismo, entre otros, su trabajo específico sobre la "Configuración de la propiedad desagregada: dualidad de derechos en la propiedad inmobiliaria", Partes I y II, RDU, núms. 138 y 139, 1994, pp. 83-170 y 97-188, respectivamente.
} 
derecho de propiedad— no podría permitir el desarrollo del concepto de propiedad urbana 0 urbanística en los términos admitidos por ejemplo en la STC $164 / 2001^{12}$.

De forma complementaria, cabría preguntarse, si alguien cree que se puede garantizar la igualdad en el ejercicio del derecho a la propiedad en materia urbanística, cuando la igualdad no cabe anudarla al derecho de propiedad, porque los derechos urbanísticos sobre el suelo siempre derivan en nuestro ordenamiento jurídico del planeamiento $y$, en especial, en primera instancia de la clasificación urbanística de ese suelo del que se es propietario. Por lo tanto, ¿puede crearse mayor desigualdad entre los propietarios, que la de clasificar a uno su suelo como urbano y a otro como no urbanizable?, ¿se evita de algún modo esta desigualdad urbanística entre los propietarios de suelo en nuestro ordenamiento jurídico? ¿El recurso al artículo 149.1.1 CE con el objeto de garantizar una pretendida e imposible "igualdad del ejercicio del derecho a la propiedad" en materia urbanística, no es una simple, ficticia o necesaria cobertura para atribuir al Estado "competencias básicas" en materia de urbanismo, que en principio no se hayan explicitadas en el art. $149.1^{13}$ ? Como se preguntaba nuestro maestro en esta materia, J. GARCÍA-BELLIDO GARCÍA DE DIEGO ¿Será posible que algún día próximo veamos que el Estado desvincula la propiedad del derecho/deber a urbanizar y edificar y retoma la propiedad desagregada que existe en todo el resto del mundo?"14.

\footnotetext{
${ }^{12}$ Al respecto, no cabe olvidar, como señala L. PAREJO ALFONSO, que aún habiendo sido admitida por la STC 164/2001, la clasificación estatal del suelo desborda notoria y rotundamente, por falta de competencia para su establecimiento, el régimen de derechos y deberes de los propietarios, que la propia Ley 6/1998 luego define. Hecho que resulta evidente si se recuerda que los criterios de clasificación del suelo tenían en el TRLS de 1992 carácter de derecho supletorio. "El régimen urbanístico de la propiedad inmobiliaria", Derecho urbanístico de Galicia, MadridBarcelona, 2001, pp. 271-272.

${ }^{13}$ Ya se sabe que el art. 149.1.1 CE hace referencia a "condiciones básicas", y que el TC ha dicho que la fijación de esas condiciones básicas no es legislación básica, pero, ¿en la práctica dónde radica la diferencia? A este propósito, I. LASAGABASTER recuerda que el TC, "hasta la Sentencia 61/1997, siempre había utilizado junto al artículo 149.1.1 CE otros preceptos constitucionales que justificaban la competencia para dictar cada norma", de tal forma que la mera "conceptuación de un derecho de propiedad urbana como derecho comprendido en la referencia realizada por el artículo 149.1.1 CE, puede llevar a estimar que en virtud de ese precepto el Estado puede entrar a regular todo tipo de materias, porque en definitiva siempre podrá verse afectado un derecho que podrá ser adjetivado según la competencia como derecho de propiedad o libertad de empresa urbana, agrícola, turística o cualquier otro término en el que se pueda pensar". "El derecho de propiedad urbana y el artículo 149.1.1 CE (Nota a la STC 61/1997, de 20 de marzo)", RVAP, núm. 50, 1998, p. 317.
}

14“"La excepcional estructura del urbanismo español en el contexto europeo", Documentación Administrativa, núms. 252-253, septiembre 1998-abril 1999, p. 78 